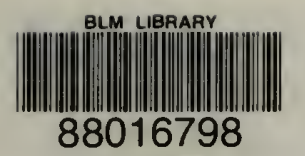

$\mathrm{T} / \mathrm{N} 338$

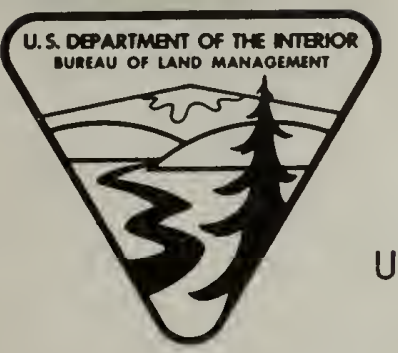

TECHNICAL NQTE7 AM 11: 14

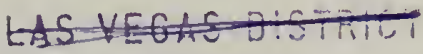

BUREAU OF

U.S. DEPARTMENT OF THE INTERTRR RTBREAU OF LAND MANAGEMENT

\title{
HABITAT MANAGEMENT GUIDES for BIRDS OF PREY
}

\section{by MAYO CALL}

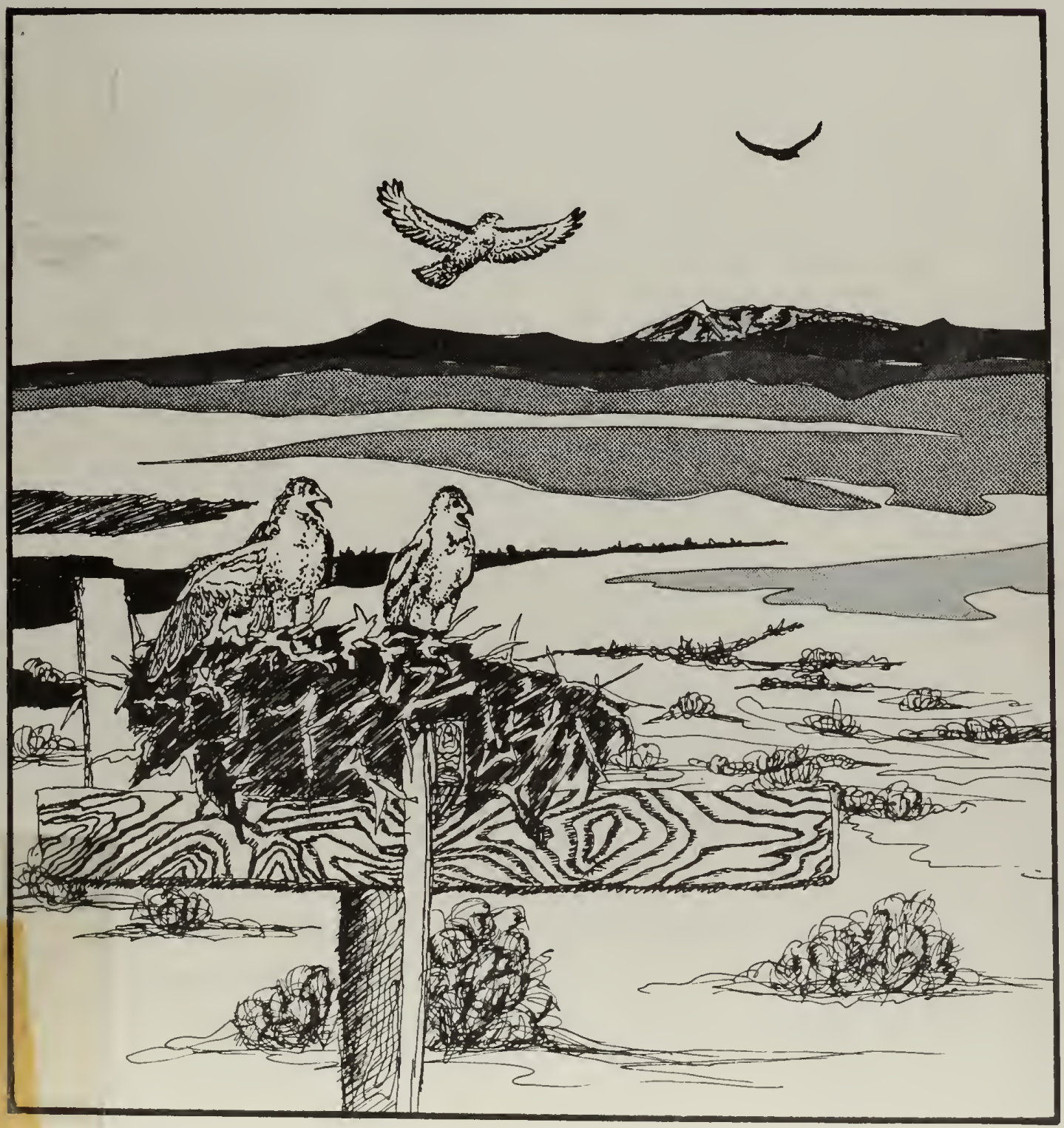

Additional copies of Technical Notes are available from DSC, Federal Center Building 50, Denver, Colo., 80225 
<smiles>[CH-]=C[SnH3]</smiles> 
HABITAT MANAGEMENT GUIDES FOR BIRDS OF PREY

by

Mayo W. $\mathrm{Ca} 11$

Avian Biologist

Denver Service Center

Bureau of land manegement

Libram

Center

Denver, co 00225

Bureau of Land Management

U.S. Department of the Interior

Denver, Colorado

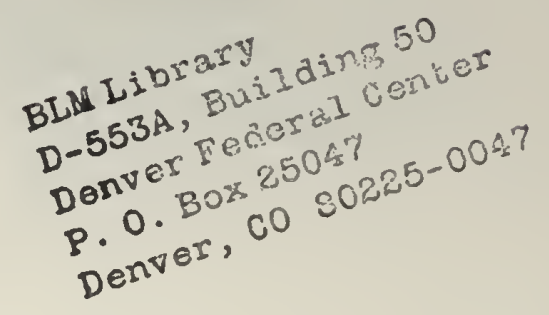


LIST OF FIGURES .................. . . iv

PHOTO CREDITS .................... . . vi

HABITAT MANAGEMENT FOR RAPTORS .............. 1

Habitat Nesting, Roosting, and Feeding Surveys ..... 3

Habitat Management Considerations in Mineral Exploration, Mining Operations, and Associated Activities ..... 3

Potential Conflicts ........... . . 4

Management Recommendations .......... 4

Habitat Management Considerations in Forestry Operations . 5

Northern Spotted Owl ............ . 6

Other Owls ................. 7

The Accipiters--Goshawk, Cooper's hawk, and Sharp-

Shinned Hawk . . . . . . . . . . 8

Management Recommendations for Accipiters . . . . 8

Bald Eagle . . . . . . . . . . . . 9 9

Recommended Restrictions within the Primary Zone . . . 10

Recommended Restrictions within the Secondary Zone . . 10

osprey ............... . . 11

Habitat Management Considerations in Livestock Grazing

Operations .................

Habitat Management Considerations in Vegetation Manipulation

Projects ............... . 15

Maintentance of Existing Raptor Habitats . . . . . . 16

Nesting Habitats . . . . . . . . . . 16

Roosting Habitats ............ 18

Protection of Crucial Habitats . . . . . . . . 20

Management of Prey Base ........... 21

Acquisition of Crucial Raptor Habitats . . . . . . 22

Management of Historical Raptor Eyries . . . . . . 23 


\section{Table of Contents}

Page

Restrictions on Human Use of Raptor Nesting/Roosting Areas. 24

Shooting Prohibitions ............. . 24

Restrictions on Rock Climbing . . . . . . . . . 26

Restrictions on Recreation Uses . . . . . . . . . 26

Restrictions on Low-flying Aircraft . . . . . . . . 28

Discretion in Raptor Surveys and Research Activities . 28

HABITAT DEVELOPMENT FOR RAPTORS . . . . . . . . . . . 30

Artificial Nesting Structures . . . . . . . . . . 30

Construction of Artificial Nesting Structures . . . . . . . 31

Cliff-Nesting Species . . . . . . . . . . 31

Tree-Nesting Species . . . . . . . . . . . . 38

Cavity-Nesting Species . . . . . . . . . . . 55

Species Nesting Underground . . . . . . . . . 57

Use of Man-made Objects for Nesting Sites . . . . . . . 57

PUBLIC I \& E PROGRAMS . . . . . . . . . . . . . . . . 63

LAW ENFORCEMENT . . . . . . . . . . . . . . . . . . . 64

LITERATURE CITED . . . . . . . . . . . . . . . . 65

ADDITIONAL REFERENCES . . . . . . . . . . . . . 70 
Figure Number

1. Artist's concept of artificial cavity that could be constructed for golden eagles, red-tailed hawks, or prairie falcons . . . . . . . . . . . . . . . . . .

2. Typical natural nesting sites of kestrels, old flicker nesting cavities, or holes in dirt banks or cliffs . . . . . 34

3. Great horned owls (left) and barn owls (right) often use cavities for nesting . . . . . . . . . . . . .

4. Nesting cavities of prairie falcons showing variety in types of cavities used and locations on cliffs . . . . . . .

5. Nesting ledge of natural golden eagle eyrie, showing normal placement on cliff . . . . . . . . . . . . . .

6. Typical nests of golden eagies showing nest size for these birds

7. Typical tree nesting sites of ferruginous hawks . . . .

8. Types of artificial nest structures that have been used to try to attract ferruginous hawks to nest. . . . . . . . .

9. Artificial nest structure occupied by ferruginous hawks near Boise, Idaho . . . . . . . . . . . . . . . . . . .

10. Artificial nest structure occupied by ravens near Boise, Idaho . . . . . . . . . . . . . . . . . .

11. Wire basket nest construction for ferruginous hawks. Chicken wire is being securely tied to branches with heavy wire . .

12. Branches and other material are placed in chicken wire basket as base for nest . . . . . . . . . . . . .

13. Completed "artificial" nest as it looked immediately after construction . . . . . . . . . . . . . . . . . . . .

14. Artificial wire basket nest utilized by ferruginous hawks the same year it was constructed . . . . . . . . . . .

15. Additional examples of artificial nests constructed for ferruginous hawks in northern Colorado . . . . . . . . . 
16. Fenced and unfenced trees containing raptor nests.

Unfenced trees are almost dead because of cattle abuse . . . 47

17. Very large active ferruginous hawk nest in very small

tree. Building a support under nest might preserve nest

for many years; otherwise it will soon topple . . . . . . 47

18. Artificial nesting burrow constructed for burrowing owls by Curtis Orde, Pawnee National Grasslands, Colorado . . . 49

19. Young great horned owlets on reconstructed ferruginous hawk nest that had been used for several previous seasons by hawks

20. Golden eagle nest in northern Colorado which was reconstructed and provided with stable base to assure more permanent nest . . . . . . . . . . . . 50

21. Artificial nesting platform used by golden eagles in northern Colorado, Pawnee National Grasslands. To date, use of such structures by golden eagles has been rare . . 50

22. Two tripod-type nest structures built for bald eagles in Arizona .. . . . . . . . . . . . . . 52

23. Bald eagle incubating on artificial nest shown in Figure 22, right-hand photo . . . . . . . . . . . . 52

24. Oregon biologist "topping" a dead snag to provide nest base for ospreys . . . . . . . . . . . . . 54

25. Young ospreys on artificial nest structure in Oregon . . . . 54

26. Section of aspen containing flicker nest cavity was placed on author's house in early winter 1979. Pair of kestrels utilized cavity as nesting site and fledged 3 young in 1979

27. Kestrel boxes placed in good locations to attract nesting birds . . . . . . . . . . . . . . . 56

28. Use of various man-made structures for nesting by raptors. . 59

29. Eagle nest platform layout and assembly (Nelson, 1978) . . . 61

30. Close-up view of nesting structure designed by Nelson (1978) for eagles and other raptors . . . . . . . . 62

31. Nesting structure for eagles and other raptors in place on steel transmission tower in Idaho . . . . . . . . . . . 


\section{PHOTO CREDITS}

Brown, Lonnie: Fig. 1 (drawing)

Call, Mayo W.: Figs. 2 (both), 3 (both), 4 (all), 5 (both), 6 (both), 7 (a11), 8 (lower right), 11, 12, 13, 14, 15 (a11), 16 (both), $17,19,20,26,27$ (a11), 28 (upper left \& right, lower left).

Canutt, Rod: Fig. 24

Gilmer, David: Fig. 28 (left center \& lower right)

Grubb, Teryl: Figs. 22 (both), 23

Howard, Richard: Figs. 8 (upper right \& left, lower left), 9, 10

Knight, Richard: Fig. 28 (center, right)

Nelson, Morlan: Figs. 29, 30, 31

Orde, Curtis: Figs. 18 (both), 21 (both)

U. S. Forest Service: Fig. 25 


\section{HABITAT MANAGEMENT FOR RAPTORS}

Habitat management for raptors may mean either: (1) the manipulation of uses and activities in an area so that birds of prey will be either benefitted or at least not seriously adversely affected, or (2) the physical change or development of the habitat such that it is more suited to the needs of one or more species, e.g., creating artificial nest sites or platforms where no suitable ones are present.

In raptor management we are primarily concerned with the perpetuation of each species (or selected species) in the face of many kinds of conflicting land uses. It should be immediately obvious that we cannot protect all birds and their required habitats wherever they are found. The development of natural resources to meet essential human needs precludes this possibility. In view of this "fact of life," biologists should determine through surveys where the most important areas are for each species and then provide these areas with the most protection from human molestation possible. Frequently, slight modifications to proposed land uses can be made to provide the birds sufficient freedom from molestation to fulfill their life requirements.

First, we need to have a basic understanding of (1) habitat requirements and food habits, and (2) bird behavior. We cannot expect to manage habitat to meet the needs of selected components of the fauna unless we understand the needs of the selected species. Further, we must understand that we cannot maximize habitat equally for all species that use the area. For example, permitting (or initiating) land use practices that will change vegetation from grass to shrub species will be adverse to kestrels and beneficial to accipiters.

The goal in land management may not necessarily be to maximize numbers of all raptors but rather may simply be to maintain the diversity of the wizd populations that can be sustained in the existing habitats. While we are becoming more involved in constructing artificial nesting sites for a variety of species of raptors in order to sustain their numbers, we must also be aware that some members of the conservation community are "turned off" by such artificial nesting habitats. To them, the goal of maximizing numbers is secondary to keeping the birds in as natural and wild a condition as possible. Most of us would agree that the sight of golden eagles (Aquila chrysaetos) nesting atop an artificial tower does not compare with the esthetic value of the same birds on a cliffside eyrie. Many factors need to be considered in determining management goals for raptors, and these will logically vary in different management units. 
Many land managers and some biologists are not aware that some species of raptors are quite susceptible to nest abandonment during certain stages in the nesting cycle. This is especially true during nest building, egg-laying, and incubation. For example, one pair each of ferruginous hawks (Buteo regalis), red-tailed hawks (Buteo jamaicensis), and Swainson's hawks (Buteo swainsoni) are believed by the author to have abandoned their nests after only one human visit to the nest. This occurred when the clutches were only partially complete ( 2 fermininous howk eggs, 2 red-tailed hawk eggs, and 1 Swainson's hawk egg). It is not known whether any further human disturbance occurred at the nest sites prior to the next visit by the author, but at the next visits all three nests were abandoned.

While some individual birds will tolerate greater amounts of disturbance than others, it has been demonstrated that a caged ferruginous hawk incurred a three fold increase in its heart rate at the sight of an approaching human (Busch et al., 1978 and unpub. M.S. thesis). Under field conditions a raptor's heart rate may increase substantialzy before the bird actually flushes from its nest. While this is not adequately documented, some unknown degree of fear or stress will cause some birds to abandon their nests permanently if disturbed when eggs are present. After the young hatch, the parents still incur stress but apparently have greater attachment to the young and will abandon less readily. The fact that some species are susceptible to nest abandonment does not mean that we should not conduct essential research or surveys on them, but simply means that we need to exercise greater caution in so doing.

The degree of susceptibility of raptors to nest abandonment seems to vary with the site on which they nest, which influences the normal neamess of approach. For example, cliff nesters appear to be less disturbed by someone at the base of the cliff than birds of prey that watch someone walk directly up to their ground nest. Birds seem to sense that their nest has been compromised when humans actually climb to it or approach sufficiently close to look into it. Neamess of approach to the nest then is one of the important factors to be considered in conducting nesting surveys. The nearness of approach to nests, frequency of molestation or visits, adaptability to disturbance of individuals (or pairs), and behavior variances among the species are all subjects of concern both to inventory specialists and to land managers. Lack of knowledge on such subjects requires that resource managers be somewhat conservative in activities permitted near nesting areas of sensitive, threatened, and endangered raptors. Less concern need be exercised for raptors that have become habituated to nesting or feeding near human habitations. This would include such species as kestrels (Falco spamerius), great horned owls (Bubo virginianus), and Swainson's hawks. (Note photo of kestrel nest on author's house, Figure 26.) 
In many cases, personnel involved in mineral exploration/development or other types of land development activities conduct their operations seemingly oblivious to the presence of much of the wildlife around them, including nesting raptors. Some of this seeming lack of awareness may be caused by the need to be attentive to the particular job at hand, but never-the-less, such persons engaged in resource "development" activities often fail to note large nests on cliffs or nearby trees or to understand the significance of "whitewash" along the edges of cavities and ledges. Much of the subsequent disturbance that occurs probably results from ignorance of the birds' presence, rather than from intentional harrassment. By having good inventories of sites used by nesting raptors (or roosting or feeding sites), resource managers can direct personnel engaged in authorized field activities away from important nesting areas, or else caution them concerning consequences, both biological and legal, that may occur if the birds are unduly disturbed during the nesting period.

This paper is intended to be only a beginning point for developing a knowledge of compatible activities between man and the birds of prey. Many other sources of raptor management recommendations are available (see Literature Cited). These should be reviewed and suggested methods tried that seem to be applicable to your specific area of concern. The following pages include management and/or development methods that have benefitted raptors in the areas in which they were used.

Habitat Nesting, Roosting, and Feeding Surveys

BLM Technical Note 316, Nesting Habitats and Surveying Techniques for Common Westem Raptors, provides some techniques for surveying nesting habitats of common western raptors. However, the biologist must be aware that many species are quite adaptable; i.e., they will use a variety of nesting sites in different regions, they will utilize the prey that is available, and their behavior patterns may vary depending on the type of habitat they occupy, their familiarity with man, or for other reasons.

After the biologist has obtained a basic knowledge of the species' nesting and feeding requirements, he will then be able to consider means for enhancing raptor habitats as a resource management objective.

Habitat Management Considerations in Mineral Exploration, Mining Operations, and Associated Activities

Many activities associated with mining exploration and/or development may either disrupt nesting or directly destroy nesting sites of various species of birds of prey. Operations conducted in winter may also cause bald eagles or other raptors to abandon historical roosts or force them away from important feeding areas. 
Potential Conflicts--Primary problems associated with mining activities during the nesting season include: (1) disturbance of birds of prey during the nesting phase with possible abandonment of nests, (2) sufficient disturbance of adults to cause missed feedings of young with subsequent mortality of young, (3) complete abandonment of territory because of excessive human disturbance, (4) complete destruction of the nest and site in conjunction with the mining operation, (5) destruction of primary feeding areas, (6) influx of personnel into the mining area with adverse impacts from their recreational use of surrounding areas, (7) frequent indifference of mining personnel to protected wildlife and their habitat, (8) inflexibility of mining rehabilitation policies to permit highwalls or other potential raptor nesting habitat to be retained after completion of the mining operation, and (9) excessive road construction or other land disturbance in immediate vicinity of mining operation.

Conflicts that may occur during the winter in areas being utilized for wintering by birds of prey include: (1) mining operations conducted sufficiently close to roosting areas so that the birds are frequently disturbed and may abandon current or traditional roost sites,

(2) prevention of use of important bald eagle feeding areas, such as along rivers or around the edges of lakes/reservoirs because of nearby mining activities, and (3) construction of mining/processing facilities in important feeding or roosting areas, including construction of processing plants, pipelines, roads, power lines, etc., and (4) actual destruction of important roosting or feeding habitat in the mining operation.

Management Recommendations--The following recommendations will help alleviate some of the adverse impacts created by mining activities and associated operations.

1. Conduct as complete an inventory as time and money permit on raptor nesting, roosting, and feeding areas. This is necessary if potentially adverse impacts of mining operations are to be adequately assessed.

2. Request that mining company officials confer with BLM land managers before commencing any field operations. This will permit BLM land managers to be aware of the geographic locations and types of activities planned, and they can then relate these to potential impacts.

3. Request mining supervisors to instruct their employees concerning the species of birds of prey that will likely be found in their area of operation and try not to molest them in their operational conduct. Advise them to avoid, when possible, destruction of raptor nests or noisy or lengthy operations in the vicinity of such nests. 
Make mining personnel aware of the legal implications of disturbing or molesting either bald (HaZiaeetus Zeucocephalus) or golden eagles (Aquila chrysaetos) or their nests. Both are fully protected under the Bald Eagle Protection Act, and the bald eagle is protected under the Endangered Species Act. Advise that a permit from the U.S. Fish and Wildlife Service is required if nests or nesting activities are to be disrupted in any way, including molestation of the birds themselves. Assure that mining personnel are also aware of the other species protected under the Endangered Species Act.

4. Mining operations, either exploratory or developmental, should not be conducted within roughly $\frac{1}{2}$ to 1 mile from active nests of eagles, peregrine (Falco peregrinus) and prairie falcons (Falco mexicanus), and some of the soaring hawks. Distance will vary according to species of raptor, terrain, amount of screening vegetation, and type of mining activity. Professional judgment must be exercised to provide some reasonable protection to the birds.

5. Advise enforcement personnel of the U.S. Fish and Wildlife Service and State wildlife agencies of legally protected birds or nests that may be adversely disturbed during planned mining operations.

6. Where winter bald eagle roosts are involved, place stipulations in construction proposals (pipeline, roads, etc.) to permit the birds some undisturbed use of the roosts at crucial times. For example, for pipeline construction, do not permit work until approximately 0900 hours in the mornings (by which time the birds have frequently left their roosts) or after such time in the afternoons that the birds will have at least one hour of daylight in which to return to the roosts for the night. While many eagles will continue to use the roosts as loafing sites during the day, some freedom from disturbing activities during early and late periods of the day will create less stress on them.

\section{Habitat Management Considerations in Forestry Operations}

A wide variety of raptors, ranging from bald eagles to pygmy owls, use forest habitats for nesting. The real factors influencing nest placement, roosting sites, and feeding areas may not be precisely known, but general characteristics of nesting habitat for each species have been described by various workers. In this section, discussion will be centered on key habitat management principles for species of high interest.

In order to manage a forested habitat for any species of raptor, we need to know as much as possible about the following parameters:

1. Distribution of raptors throughout the area.

2. Interspecific competition and/or tolerance. 
3. Description of most commonly used nesting site.

a. Kinds of trees used for nesting.

b. Size of trees and most common location of nest in tree.

c. Density of trees at nest site and in surrounding area.

d. Use of secondary canopies or understory trees.

e. Approximate territory size in a given forest type.

f. Use of alternate nest sites.

g. General tolerance of the species to various forestry activities.

h. Importance of snags or large mature trees for roosting, perching, sunning, plucking, nesting, etc.

i. Distribution and relative abundance of prey species.

j. Water requirements.

4. Availabilty of suitable, alternate nesting locations.

5. Probability of recycling, or re-nesting, if the first nesting attempt fails.

When information on several of the above parameters is lacking, it is always advisable to be conservative in the types of activities to be authorized in the proximity of active nesting sites. The amount of disturbance tolerated by most raptors is much less during egg-laying and incubation than after the young hatch. Permitted activities may vary depending on the nesting phase of the particular species.

\section{Specific Habitat Considerations}

Northern Spotted Owl (Strix occidentalis caurina)--The northern spotted owl is almost completely habitat specific to old growth forest in Oregon, Washington, and northern California. Management area parameters prepared by BLM, Forest Service, and Oregon State University are as follows (based on existing knowledge in October 1977, and subject to change as new research is forthcoming):

Territory Size--Minimum size should be 1,200 contiguous acres per pair (i.e., one home range).

Habitat Description--Each pair should have a core area of at least 300 acres of old growth forest. If 300 acres of old growth does not exist, then maintain all remaining old growth and enough of the oldest contiguous or closely adjacent second growth to total 300 acres. The remainder of the habitat should be managed to provide at least 50 percent of the acreage in stands of 30+-year-old forests. Old growth forest must be at least 200 years old and contain an average of eight to ten old growth overstory trees (minimum of four) per acre, with a developed understory greater than 30 years of age. 
Number of Pairs--The management area should encompass the home ranges of a minimum of three pairs, with six pairs ideal. Single pair enclaves are acceptable in peripheral situations, such as in eastern Oregon, or where remnant habitat exists.

Proximity of Pairs--Core areas for each pair should be separated by approximately one mile, center to center.

Distribution throughout Known Range--As a goal, management areas of three or more pairs should be eight miles, not to exceed 12 miles, apart. Single bird management areas should be five miles, not to exceed eight miles, apart.

Northern spotted owls freqently roost in summer in close proximity to small streams or springs that apparently cool the lower levels of the forest habitat. Such moist areas should be given special consideration in spotted owl habitat management plans.

Other Owls--The large variety of owls other than spotted owls that nest in forested areas makes it difficult to manage large areas of forest for any specific species, since they have varied requirements. Pygmy owls (Glaucidium gnoma), saw-whet owls (Aegolius acadicus), flammulated owls (Otus flammeolus), screech owls (Otus asio), and elf owls (Micrathene whitneyi) are all small species that nest in various kinds of habitats within forests or in scattered clumps of trees. Only general rules should be applied for management of the group as a whole.

One thing all small owls have in common is their nesting site, which is almost always some type of woodpecker or flicker hole or other cavity in a tree, cactus, or similar type of vegetation. Since they all nest in some type of cavity, the big emphasis should be on snag retention and management in all forestry programs. Publications by the Pacific Northwest Forest and Range Experiment Station at La Grande, Oregon, discuss differences in cavity requirements and utilization by various kinds of birds. It is likely that the various species of small owls also have unique preferences for specific locations or kinds of cavities. A general program of snag retention would be advised until more specific nesting habitat requirements are available.

Several species of larger owls, including the long-eared (Asio otus), great horned (Bubo virginianus), great gray (Strix nebulosa), and barred (Strix varia), will be found nesting in other raptors' nests, either in dense or mixed forest stands. They will also utilize large cavities in trees, such as those which occur during decay or from wind breakage, so the importance of retaining old, decadent trees or snags may also be important for the larger owls. Since large owls do not construct any kind of stick nest themselves, the preservation of as many stick nests of other large birds as possible should be another management objective. 
The Accipiters--Goshawk (Accipiter gentilis), Cooper's Hawk (Accipiter cooperii), and Sharp-Shinned Hawk (Accipiter striatus)-Various researchers have described subtle differences in nesting habitat requirements for each of the three accipiters (Shuster, 1979, in press; Reynolds et al., 1978; Jones, 1979). Differences in primary nesting habitats are also apparent in different regions of the continent. Over much of Alaska, goshawks nest predominantly in deciduous trees, while from Canada south most of them nest in coniferous trees. Structure and size differences between the two tree types are obvious. Some of the more common differences in nesting sites between the three species are as follows:

Goshawk--These birds commonly nest on benches or basins surrounded by much steeper slopes. In Oregon, goshawk nests were in stands of conifers, ranging from those with closed mature canopies and few shade-tolerant understory trees, to stands with more open mature canopies and many understory trees, effectively producing multi-layered canopies that began a few meters above the ground and rose to above 60 meters. In Colorado most nests were in the older mature trees of a stand and were more often on gentle slopes than on steep slopes.

Cooper's Hawk--These hawks are generally considered to be lower elevation birds than the goshawks. They commonly nest in trees, both coniferous and deciduous, along the bottoms of draws and other stream sources. It is not uncommon to find their nests in the mountain brush zone of mountain slopes.

Sharp-Shinned Hawk--This species frequently nests in relatively dense stands of second-growth conifers, or in dense stands of mountain brush or hardwoods.

Reynolds et al. (1978) stated that the principal differences in vegetation structure among the three species were associated with successional age of the stands: sharp-shinned hawks nested in 40-to-60-year-old, evenaged conifer stands; Cooper's hawks in 50-to-80-year-old, even-aged conifers with somewhat larger and more widely spaced trees, and goshawks in 100-to-150-year-old conifer stands. While this research was accomplished in the Northwest, general differences in successional stages of trees as nesting sites seem to apply throughout the West. With regard to vegetation density, goshawks seem to nest most commonly in the least dense vegetation, while sharp-shinned hawks nest in the most dense areas.

Management Recommendations for Accipiters--According to Reynolds (in press) and Shuster (1979, in press) and based on nest site requirements, the following management measures are recommended:

1. Inventory nest sites using criteria for most common nesting habitats. 
2. Request all resource staff specialists to report any nests located during routine work.

3. Leave an undisturbed area around Accipiter nests such that the area includes much of the stand upslope from the nest, all plucking and roost sites, and at least some portion of the stream or spring (if one is close by the nest site). The shape of the leave area will be determined by the topography and shape of the stand of trees at the individual nest sites.

4. Nests should not be isolated by any silvicultural treatment, such as clearcutting, commercial thinning, etc.

5. Nests discovered during logging activities should be protected from further disturbance within $3 / 10$ mile $(0.5 \mathrm{~km})$ of the nest. This is especially important during early stages of nesting, generally from March thru May.

6. Snags and fallen and arched trees should be preserved in forest stands to serve as perches and plucking sites.

7. In timber management, try to develop diversity in both tree age and forest density. Even-aged stands are poor nesting habitat for goshawks and are less than ideal for the other two species.

Bald Eagle (HaZiaeetus ZeucocephaZus)--Bald eagles and ospreys (Pandion haliaetus) commonly nest in trees bordering streams or lakes. Osprey nests are most frequently constructed in the tops of dead trees, but bald eagles may nest either in the tops of dead or living trees or on strong supporting branches below the canopy.

General guidelines for habitat management for bald eagles are presented in the publication by Region 5, U.S. Forest Service, entitled Bald Eagle Habitat Management Guidelines and in the guidelines prepared by the U.S. Fish and Wildlife Service for the Pacific Northwest entitled Bald Eagle Management Guiderines: Oregon-Washington. Both sets of guidelines refer to management of primary and secondary management zones. The primary zone is the most critical area immediately around the nest. The secondary zone is the additional buffer area immediately adjacent to the primary zone. Areas recommended for protection in either zone apply to both active and alternate nests, since alternate nests may be used in different years. The same guidelines would apply equally to golden eagles that are found nesting in forested areas.

As defined by the Fish and Wildlife Service, the protected area of the primary zone should include all area within 300 feet ( 5 chains) of the nest, except under unusual circumstances where a particular pair of eagles is known to be tolerant of closer human activity. The size of the protected area should be adjusted by the actual use of the area around the nest tree to include frequently used perch trees. Where isolated groups of trees are likely to blow down, the primary zone 
should not be less than 20 acres, and the opinion of a qualified forester should be obtained in order to take measures to minimize that likelihood.

Recommended Restrictions within the Primary Zone--The following human activities are likely to cause disturbance to eagles and, therefore, should not occur within the primary nesting zone at any time:

1. Major land uses such as logging, the development of new commercial and industrial sites, the building of new homes, roads and other construction, and mining of any kind.

2. Use of chemicals toxic to eagles. These include DDT, other persistent organochlorine pesticides, PCB, mercury, and lead.

In addition, certain human activities are likely to disturb eagles during the critical period of nesting, which is defined as the time between the arrival of adults at the nest site and three weeks after the fledging of any young. This period will vary in different geographic locations depending on elevation and other factors which influence the birds' nesting chronology. In most locations the critical period will probably be between February 1 and August 1. Eagles are most vulnerable to disturbance during the first 12 weeks of the critical period. Therefore, during the critical period there should be no human entry into the primary nesting zone, and there should be no permited low-level aircraft operations.

Additional management recommendations for public lands (and waters) may include: (1) closing land and water access to the nest, (2) posting the boundary of the area, if necessary, to reduce travel near the nest (without specifying the presence of an eagle nest), (3) prohibiting recreational activity entirely or seasonally, and (4) permitting only the necessary research and management activities near or at the nest site.

Additional management recommendations for private lands and waters may include: (1) working with the landowner to encourage him to voluntarily protect the primary zone around the nest, (2) acquire or encourage another agency or conservation organization to acquire the area in fee, by easement, or by exchange.

Recommended Restrictions within the Secondary Zone--Certain human activities of a permanent nature are likely to disturb eagles and/or potentially cause nest desertion and should not, therefore, occur within the secondary zone at any time. Such activities include development of new commercial and industrial sites, building of new homes, building of new roads and trails that may increase access to the nest, and use of chemicals toxic to eagles. 
Certain human activities have time-limited effects that may be adverse to nesting birds. Because of this, human entry into the secondary zone should be avoided during the critical nesting period. Examples include disturbance from logging, selective cutting, and other forestry activities; mining; low-level aircraft operations; use of firearms; camping; and picnicking. Occasional and limited human intrusion such as hiking, bird watching, and fishing should not be disturbing in most cases. Land modifications, such as permanent campgrounds, boat launching facilities, gravel pits, roads, etc., would encourage excessive use and should not be permitted in the secondary zone.

If a pair of eagles chooses to establish a new nest in an area already receiving human use, the human activities occurring at that time can continue, except the use of toxic chemicals. Any expanded human activity should be avoided.

Additional management recommendations for the secondamy zone would include those stated for the primary zone. Special caution must be exercised during the two weeks prior to anticipated fledging of the young eagles. If disturbed by humans during this period, the young birds may attempt to fly prematurely, possibly damaging wing feathers, bones, or causing internal injuries. Also, the birds may not be able to regain flight again if they end up on the ground.

In addition to the recommendations for active nest sites provided by the U.S. Fish and Wildlife Service (1977), they also suggest the following actions for potential nest sites:

1. In potential or traditional eagle nesting habitat where no nest now exists, for every 320 acres less than $\frac{1}{4}$ mile from a river, lake larger than 40 acres, or tidewater, leave four to six overmature trees in the stand with an open view of and clear flight path to the water in an area free of human disturbance. These should be the largest trees in the stand and preferably have dead or broken tops. In addition, four to six mature trees (80-year-old) should be left to provide nesting sites over the long-term period (50 to 100 years).

2. Since eagles have been known to reoccupy a nest unused for several years, do not remove old nest trees, even though they have been seemingly abandoned. Trees in the surrounding zone should also be protected until the nest is destroyed by the elements.

Osprey (Pandion haliaetus)--Human activities can significantly influence productivity, especially in colonial nesting areas where disturbance could adversely affect several breeding pairs of ospreys simultaneously (Zarn, 1974). Therefore, for ospreys Kahl (1971, 1972) recommends implementing the following protective measures whenever possible: 
1. Permit no human activity within $200 \mathrm{~m}(650 \mathrm{ft})$ of any active osprey nest and restrict all vehicular traffic to roads not having portions lying within $200 \mathrm{~m}(650 \mathrm{ft})$ of any active nest, from April 1 to September 15 .

2. Close nesting areas to hunting or shooting between April 1 and September 30. Hunting may be permited after September 30, as most ospreys have migrated south by then.

3. Prohibit tree or snag cutting by private individuals in close proximity to lakes, reservoirs, and streams.

4. Permit no overnight camping in or near osprey nesting areas from April 1 to September 15.

5. Construct no developments excepting osprey habitat improvements. Walking trails and public observation points for viewing ospreys (if desired) should be placed so as not to disturb the birds or their activities.

\section{Enforce all regulations protecting ospreys.}

\section{Habitat Management Considerations in Livestock Grazing Operations}

The primary effect on raptors of livestock grazing is an indirect influence produced by changes in the vegetation composition, density, and structure. Such changes in the vegetation produce concurrent changes in the composition and populations of the fauna (small mammals, birds, reptiles, and amphibians) that utilize the grazed (or browsed) habitat.

As browse ranges gradually change to grass, or vice-versa, the fauna will be favored whose habitat needs are best met by the new habitat conditions. For example, prairie dogs (Cynomys spp.) do not do well in dense stands of sagebrush; conversely, Brewer's sparrows (Spizelza breweri) are largely habitat-oriented towards sagebrush and are seldom found in grassland habitats. Through this ecological mechanism, livestock grazing indirectly causes changes in the prey base available to raptors using the area. The species of raptors will be most favored whose food needs will be met by the fauna residing in the local habitats. Golden eagles and ferruginous hawks do best where the habitats favor the production either of rabbits (Lepus and Sylvilagus spp.), prairie dogs (Cynomys spp.), or ground squirrels (Citelzus and Ammospermophilus spp.).

Changes in the density and structure of brush habitats are frequently beneficial to raptors. Lower vegetation with lesser density tends to make small rodents and lagomorphs more available, or vulnerable, for capture by foraging raptors. Moderate to heavy livestock grazing of sagebrush for several consecutive years in winter reduces the vigor of 
the brush, causing the death of many of the plants and helps to open up the area. Moderate to heavy grazing of grassland areas also removes much rodent cover and may be especially beneficial to birds of prey during the nesting season. Thus, cover manipulation provides one opportunity for improving predation success by raptors.

Improved predation success for raptors as the result of reduced cover for their prey may be partially offset by possible prey reduction on overgrazed ranges or ranges in poor condition. Craighead and Craighead (1956) stated that ranges in good condition provide a greater abundance of prey than ranges in poor condition. They also stated that golden eagle numbers would probably decline in areas of poor range condition. According to Anderson (1972), there is a definite reduction of density and diversity of both rodents and birds with heavy livestock grazing. While relatively high populations of lagomorphs and certain rodents are sometimes observed in heavily grazed areas, it is probably more a function of irregular cyclic fluctuations or favorable conditions over short periods than it is a result of overgrazing.

Golden eagles and some other raptors occasionally prey on sage grouse (Centrocercus urophasianus) and blue grouse (Dendragapus obscums). Habitat desirability for sage grouse declines as the sagebrush understory of grasses and forbs decreases, or as sagebrush height increases beyond about 15 inches. Grassland ranges that are gradually converting to sagebrush would be improving for sage grouse until the percent of sagebrush in the composition exceeds approximately 30 percent. Continuation of high grazing use in most low and middle elevation areas would cause a gradual decline in the grass and forb species, making the habitat less suitable for grouse.

Goshawks feed quite heavily on blue and ruffed grouse (Bonasa umbellus) in some parts of the country (Eng and Bullion, 1962). Production of these grouse is partly dependent on the quality of their nesting and brooding habitat. In the West, wet meadows and/or stream bottoms are of paramount importance to grouse for brooding their young. These areas are among the most heavily grazed by cattle, making them less suitable for grouse. Green plant parts, seeds, and berries are needed by adult grouse, while the young utilize large quantities of insects associated with these areas, as well as green grass and other plant parts. Grouse use these areas for raising their young at the same time that cattle may be using them in the spring months.

Trampling of wet meadows increases erosion and generally decreases their quality as grouse brooding habitat. If the meadows are in good condition, they are also utilized by many kinds of small mammals, birds, and reptiles, all of which may provide additional prey for resident raptors. Ruffed grouse are more frequently found in dense vegetation along stream bottoms or on hillsides covered with mountain brush. Grazing practices that deplete grasses and/or forbs in such areas will be detrimental to this species just as for the blue and sage grouse. 
On high desert ranges, short grass prairies, or other vegetation associations that contain very few trees, cattle often create an additional adverse impact. As described by Olendorff and Stoddart (1974), the death of the few available nesting trees is often hastened by cattle that seek shade from them or use them as rubbing posts. The vegetation and soil at the base of the trees become trampled; wind blows the loose soil away; and the exposed roots eventually die. Combined with the rubbing of the tree bark, the trees finally die. A high percentage of the trees on the Pawnee National Grasslands of northern Colorado, whether planted by early homesteaders or growing naturally along intermittent water courses, have been used by a wide variety of birds of prey for nesting for several decades. Birds like the ferruginous hawk will continue to use the trees for nesting until they finally topple. Where trees are very scarce in such areas, they should be fenced to prevent damage by livestock. They are not that important as livestock shade but may be highly important as raptor nest sites. The need to preserve the available nests in such trees was discussed by Olendorff and Stoddart (1974), and the techniques are presented in a later section of this publication. In areas where ferruginous or other hawks most commonly use trees as nesting sites, the preservation of such trees is especially important. Ferruginous hawks most often construct tree nests throughout Colorado and in southern Idaho, for example, while they nest predominantly on the ground or on rocky outcrops in southern Wyoming.

It is unlikely that actual trampling of ground nests by livestock is of any consequence. Nests of marsh hawks (Circus cyaneus) and short-eared owls (Asio flammeus) are sufficiently scattered so that there is very little likelihood of a chance encounter of a nest by either sheep or cattle. There is little information available relative to the behavior of ground-nesting raptors when approached closely by either cattle or sheep. Patterson (1952) reported that sage grouse sometimes abandoned their nests during the early stages of incubation if disturbed frequently by foraging sheep but seldom abandoned their nests during the late stages of incubation. During his intensive sage grouse study, he recorded no instances of sheep destroying eggs by actually stepping on them. However, in a few instances, the sheep caused the birds to flush and simultaneously to flip eggs out of their nests with loss of the eggs, and sometimes, nest abandonment. Whether marsh hawks and/or short-eared owls are more tenacious while on their nests and their reactions to livestock are not known.

In most areas of the West and Southwest, riparian zones are heavily grazed by domestic livestock. One effect of this grazing has been the destruction of sapling cottonwoods (Poplar spp.), aspen (Populus tremuloides), and other tree species that are the primary nesting sites of numerous species of raptors. Especially in the Southwest, the critical nesting tree, the cottonwood, for several peripheral buteos [black (Buteogallus anthracinus), zone-tailed (Buteo albonotatus), and 
gray hawks (Buteo nitidus)] is not replacing itself in many areas (Snyder and Snyder, 1975; Glinski, 1978, personal commun.). Cottonwoods and other trees of the riparian zone in many regions are replacing themselves only in areas that are not grazed by cattle. Grazing management systems established by land managing agencies must take this problem into consideration if species of raptors in these areas of critical tree shortage are to be maintained.

\section{Habitat Management Considerations in Vegetation Manipulation Projects}

Several investigators on the nesting ecology of the ferruginous hawk in northern Utah and southern Idaho have mentioned the potential vulnerability of these birds to revegetation projects and other land use alterations (Murphy, 1978; Platt, 1971; Howard, 1975; Woffinden, 1975). Ferruginous hawks used Utah juniper (Junipems osteosperma) for nesting in 95 percent and 66 percent of the nest sites in the studies by Howard and Woffinden, respectively. Woffinden (1975) also pointed out that nest trees are not randomly selected, but Zone or peripheral trees are preferred. Murphy (1978) reiterated that the nests, therefore, are not randomly distributed throughout the intermontane valleys but instead occur in clumps around the periphery of the valleys. Because of this fact, Murphy (1978) recommended that wherever range rejuvenation projects involve the destruction of juniper stands, individual trees or a thin screen of trees be left standing near valley margins.

While the removal of nesting trees may be adverse to certain species of raptors whose behavioral instincts impel them to nest in trees, this is not the only significant impact caused by vegetation conversion projects. Conversion of brushlands to grass to benefit cattle will alter both the species of prey present in the area and their populations. It is especially disrupting to production of both jackrabbits and cottontails that survive best in mixtures of brush and grassland types. Such changes are probably most adverse to ferruginous and red-tailed hawks and golden eagles. Swainson's hawks normally use a wider variety of grassland prey, including a variety of small bird species and their young and a mixture of the larger insect species, such as grasshoppers. By knowing the specific prey requirements of the various raptors, particular species of raptors may be either benefitted or adversely impacted by different kinds of vegetation conversion projects. Those species of raptors whose local, regional, or national populations are known to be declining should be given highest management priority.

Where possible, areas of brushland habitat should be retained in scattered patches within the planned vegetation treatment area. This will help maintain the prey species that many of the nesting raptors depend on in that particular area. While little control of private land vegetation changes can be exercised by Federal or State officials, there are some areas where exchange of use is a common practice and where some control can be accomplished. Exchange of use occurs where boundaries 
between public and private ranges are not fenced and the livestock operator is licensed to use the entire area during a given season(s) with the total amount of forage to be used agreed upon by the private landowner and the public land administrator. In such areas the landowner may agree to certain stipulations in use of his private land (for the benefit of raptors or other wildlife) in exchange for the specified use of the public lands.

\section{Maintenance of Existing Raptor Habitats}

Nesting Habitats--Insofar as is feasible in the face of resource developments to meet increasing human needs, existing nesting sites or eyries should be protected and maintained in their present condition. Raptors nest where they do because of innate behavioral instincts that guide them in their selection of nest sites. Some species are extremely specific in their selection of nesting sites, while others appear to be very adaptable. Management priorities should be directed towards those species that are most habitat or site specific in their selection of nest sites. For example, cliff-nesting species such as peregrine falcons need greater protection of traditional nesting eyries than do kestrels. Eagle nesting sites are more critical than those of ferruginous hawks (since ferruginous hawks nest in a much wider variety of sites).

Many species of raptors maintain alternate nesting sites which are used at the birds' discretion on an irregular basis. Alternate nests are usually in the same kind of site as the currently active nest and are often clustered in a relatively small area, commonly less than a mile in diameter. Distance between alternate golden eagle nests may be a little farther, while ferruginous hawk nests may be grouped along a rocky outcropping just a few hundred yards apart or less. Distance between alternate nest sites depends largely on the availability of suitable nesting substrates in the particular area. For example, the distance between nest sites of tree-nesting golden eagles in areas where trees are scarce will depend on the nearness of suitable trees. In an area of western Wyoming, four active golden eagle nests lie generally in a line in scattered cottonwood trees that have developed along a foothill canal. The nests are approximately one to three miles apart, and no alternate nests are presently known. Most of the other cottonwood trees in the area do not have adequate branches for supporting the large nest of an eagle. All four nests are on private land. The destruction of these trees by the private landowners for any reason would probably mean the elimination of the pair (or pairs) of eagles from the area. Interestingly, one of the pairs of eagles nests in a group of cottonwoods that lie within a pasture where sheep lambing occurs each spring. No evidence of eagle predation on the sheep has been reported, and it is unlikely that the landowner is unaware of the presence of the birds in their conspicuous nest. 
The preservation of alternate nest sites is just as important as the preservation of the currently active nests, since they will be used intermittently over the years.

In considering the need to maintain existing raptor nesting sites, we must consider what would be lost if the sites were eliminated. Cliff sites are in limited supply throughout many parts of the West and are essential for nesting by many species of raptors, such as peregrine falcons, prairie falcons, and most golden eagles. The loss of cliffs generally means an irreplaceable loss of key nesting habitat, since cliffs cannot be economically reconstructed. A substitute for cliffs being used by some cliff-nesting raptors is the high walls produced by surface mining of coal and some of the hard rock minerals. The use of such high walls for nesting by golden eagles, prairie falcons, and great horned owls has been documented. Unfortunately, State and Federal laws on mining reclamation do not permit permanent retention of high walls because of safety and pollution hazards, erosion problems, and general loss of land production. But, in many situations, high walls would serve as substitutes for natural cliffs that had been destroyed or they provide nesting sites for cliff-nesting raptors where no natural cliffs had existed before. In such situations a new type of habitat could be developed that had not existed before and could be of greater importance than returning the land to its original topography and production. Inflexible laws and regulations could prevent land managers from producing wildlife habitat that is actually more valuable than the habitat that was destroyed by the mining (or other) activity.

The loss of tree nesting sites may be a serious temporary or short-term impact but, given time, trees can be replaced if desired. In the absence of trees, nesting platforms are acceptable to some birds of prey. Power lines are also being used as nesting sites by golden eagles, red-tailed hawks, ferruginous hawks, great horned owls, Swainson's hawks, and ravens (Comus corax) where natural, elevated nesting sites are not available. In general, however, trees that contain nests should be retained whenever possible because of their proven value as nesting sites. We can never be sure that artificial nesting platforms will be utilized by the desired species.

Specific nest sites of ground-nesting species are not as crucial as tree and cliff sites, because there is generally a greater abundance of potentially suitable sites. Marsh hawk, short-eared owl, and ferruginous hawk nests have been found in a wide variety of ground habitats throughout the West. Also, ground-nesting species do not normally use the same nesting site on subsequent years (except for ground-nesting, ferruginous hawks that sometimes use the same ground nest for several years). The author does not believe that most populations of groundnesting raptors will be seriously affected if occasional nests are destroyed by land development activities. This may be subject to differing opintons, but in many areas ground-nesting opportunities are almost unlimited. 
Protection of snags for cavity-nesting species is very important. In the past, snags have been largely eliminated during timber harvesting operations with a concurrent loss of nesting sites for a variety of bird species, including a multitude of passerines, woodpeckers, and owls. Saw-whet, screech, elf, pygmy, flammulated, barred, spotted, hawk (Sumia ulula), and great horned owls will all utilize cavities in trees for nesting. The small owls normally use holes made by woodpeckers or flickers (Colaptes spp.), while larger owls may nest in cavities created by broken tops or branches or in decaying cavities in the tree. Loss of snags over wide areas during timber harvesting operations may cause significant reductions in populations of birds depending on cavities in trees for nesting sites. Every effort should be made to retain as many snags as possible during timber harvesting operations.

Dead trees are commonly taken by woodcutters when they are readily accessible or close to roads. In such areas land managers may want to place signs on selected trees to indicate they are important for wildlife and are not to be cut. Studies by Thomas et al. (1979) are a good reference for the numbers of snags required by different species of birds.

Roosting Habitats--Communal roosting behavior is encountered in a wide variety of habitat situations and undoubtedly confers some survival advantage upon the participants (Murphy, 1978). Such roosts are probably selected because they offer special advantages to the birds, such as proximity to feeding areas; protection from wind, snow, rain, cold, etc.; favorable exposure to sun; favorable updrafts to the site; isolation; or for other reasons. Removal of such roosts or creation of disturbance sufficiently near the roosts to cause their abandonment may cause an additonal stress on the birds that could affect their survival. Agencies having land management responsibilities should locate, map, and provide the appropriate management classification to protect them from incompatible uses.

Roost trees are usually large enough to provide safety from any predatory threat from the ground (U.S. Forest Service, 1977). They are typically the largest trees in the stand; the crown near the top or the middle portion of the tree must be open and have stout lateral limbs with reasonable access for the large birds.

Many large bald eagle winter roosts are known throughout the United States, and many smaller ones are scattered in between. Because biologists are uncertain as to potential effects produced by the destruction of such roosts, it is considered advisable to protect all roosts to the greatest possible extent. Any bald eagle roost containing more than five birds should be given complete protection. While it may be argued that a few scattered bald eagles along a river bottom or elsewhere may have unlimited sites at which to roost, we should not overlook the possibility that subtle factors of exposure, tree height, limb jize and 
structure, or other factors may be important in their selection. Legal requirements of both the Bald Eagle Protection Act and the Endangered Species Act suggest that maximum protection be provided both nests and roosts (or any other identified crucial areas).

Disturbing activities, such as pipeline construction, oil and gas drilling operations, etc., should be permitted only during seasons when the eagles have migrated out of the area and have not returned to either nest (in northern latitudes), to spend the winter (in more southern latitudes), or during times of the day that will be least disturbing to eagle activities.

Biologists should try to recognize signs of eagle reactions to human presence and disturbance. Bald eagles exhibit great variation in response to human activities depending on the type, frequency, and duration of the activity; types of modifications being made in the physical environment; time in the birds' reproductive cycle; and individual bird's tolerance to disturbance. Eagles seem to tolerate a degree of human presence, but there is a threshold level beyond which they will leave the area, perhaps being forced into less desirable habitat.

There is some indication that snowmobile activity may be adversely affecting both the nesting and roosting of bald eagles in some areas (U.S. Forest Service, 1977). Eagles have abandoned territories after a long period of occupancy where the levels of activity to which they were accustomed were gradually increased. Such abandonment may take several years before it occurs, possibly indicating a gradual increase in stress level as human activity increases. Human disturbances may be both quantitative and cumulative. A conservative assumption would be that bald eagles need some degree of isolation from disturbing activities in order to carry out their essential life functions at critical times. The extent of this need for both spatial and psychological isolation varies from case to case and should not be generalized.

Many winter roosts are in western valleys located on private lands; in such cases it may not be practical to purchase tracts of land to convert them into bald eagle sanctuaries as has been done by private conservation organizations in some parts of the country. However, agency personnel and others interested in the welfare of eagles can often form effective liaisons with landowners and develop in them a cooperative attitude and proprietary interest in maintaining the roost area in a manner that will minimize disturbance. Interestingly, bald eagles may choose to roost in large trees bordering small towns and farms in some locations, even though mountain roosting sites are within easy flight range. At Vernon, Utah, bald eagles have roosted in winter near human habitations for several years. By their oun choice, these birds roost very near disturbing activites (dogs barking, boys shouting, vehicular traffic) that most eagle biologists would consider untenable for the birds. Such tolerance for humans by individual birds is similar to that of some eagles that 
have nested close to human dwellings in Washington State (Grubb, 1978, personal commun.). However, we must not try to apply this behavior to the species as a whole, because the bulk of the population is known to be more sensitive to human intrusions.

Protection of Crucial Habitats--Several species of raptors have significant traditional use areas for nesting, roosting, or feeding to which the species are largely tied for their survival. California condors (Gymnogyps califomianus) are surviving only in selected parts of California; peregrine falcons of the interior West are now nesting in a very limited number of active eyries; major numbers of bald eagles migrate southward from Canada to spend their winters in various size groups in selected areas; black, zone-tailed, and gray hawks are somewhat limited in their nesting distribution to specific canyons and river bottoms in Arizona, with only a few scattered pairs of black and zonetailed hawks found in adjacent states (the United States only); Mississippi kites (Ictinia mississippiensis) are found nesting only in certain river bottoms of Colorado and Arizona in these two states. Many other examples could be given of restricted use areas of specific species.

These very limited use areas in several states may be classified as cmcial areas. They may be of great importance to the survival of the species within a state or for the species as a whole. In either situation they should be provided maximum protection. This is in contrast to raptors that are relatively common and that may nest irregularly and in a wide variety of habitats over vast acreages. A review of the literature will reveal the primary distribution of the different species and their primary nesting and wintering areas. From this information the biologist can determine areas that should be surveyed to verify their presence and to delineate the important habitat areas under various management jurisdictions.

The more habitat specific a species is, the more vulnerable the species is to changes or loss in their special habitats. Since ospreys are completely tied to fish-bearing bodies of water, they are much more adversely affected by changes in these specific sites than are redtailed hawks that utilize habitats varying from dense tropical rain forests of Puerto Rico to western deserts to Alaskan taiga. The degree to which a raptorial species is tied to a specific habitat type and the extent of that habitat type will determine the urgency for providing the special considerations to that species in land use decisions. Very limited habitats occupied by raptors should be classified and protected as critical habitats. On-the-ground judgment must be exercised by the biologist to determine how much area within the specific habitat type should be protected against conflicting uses. Such determinations will be influenced by distribution, numbers, and availability of the required prey base; location of required habitat components (for nesting, roosting, etc.), and the influence of various human activities on the behavior of the birds. If knowledge is lacking, be conservative in the birds' favor. You can always decrease the size of protected areas if forthcoming data shows greater tolerances to disturbances than originally thought. 
It is important not to advertise site specific nesting or roosting areas. While specific locations may need to be revealed to selected land managers and planners, general knowledge of nesting sites of endangered or threatened species frequently encourages their visitation by photographers, nature lovers, and others whose very presence may cause nesting failure or abandonment of choice roosting sites. It is natural for birdwatchers to desire to view unusual or rare species, but ardour sometimes needs to be tempered with wisdom.

Management of Prey Bases--Many of the small mammal species utilized as prey by various raptors are known to be irregularly cyclic in their population fluctuations. Populations often change because of intrinsic factors that have little relationship to their habitat. A frequent cause of small mammal population declines is density related stress which occurs because of frequent encounters with members of their own species. Rabbits are also known to be more or less regularly cyclic, and the raptors which prey on them may either fail to nest or have poor production during the years when the rabbits are at a low point in their population cycles. Little can be done to manipulate rodent or rabbit cycles.

The most productive management of prey, as with alz wildlife, comes from management of the habitat so as to produce the desired fauna. The term "desired" is somewhat philosophical, since each group or species of animal usually has its own devoted advocates. However, certain raptors, such as bald and golden eagles, peregrine falcons, ospreys or other species which have either State or Federal protected status, will have priority in land management programs. Management of prey bases for such priority species might include maintenance of wetlands for shorebird and waterfowl production for utilization by peregrines; perpetuation of prairie dog colonies through suitable grazing practices as a prey source for golden eagles, prairie falcons, and ferruginous hawks; and maintenance of suitable habitat conditions in rivers, lakes, or reservoirs for fish production for bald eagles and ospreys. Range management practices that produce or maintain ranges in good condition will provide a greater abundance and variety of prey for a multitude of raptorial species. We must be especially careful about the use of pesticides or rodenticides distributed to destroy rodents, rabbits, or other fauna that may be crucial to the survival of the raptors present.

A further consideration is that larger species of raptors normally utilize larger forms of prey. Average size of prey utilized by various raptors include: golden eagle--1,825 g; ferruginous hawk--1,394 g; red-tailed hawk--1,386 g; and Swainson's hawk--905 g (Smith and Murphy, 1973; Olendorff and Stoddart, 1973). Therefore, the prey species that should have priority in management programs will depend somewhat on the raptor species selected for primary management efforts. Also correlated with this is the statement by Lack (1966) that "the large prey on which large raptors depend are in general much sparser than the small prey on which small raptors depend...." 
The widespread poisoning of prairie dogs during the last two decades in southern New Mexico is believed to have been responsible for the disappearance of ferruginous hawks in the area (Hubbard, personal commun.). Reasons for the decline in birds could have been indirect poisoning or simply a reduction in their primary prey.

In flat prairie or desert country where natural, elevated observation or feeding perches are very scarce, artificial perches may be erected for use by raptors. Artificial structures such as power poles receive high use by eagles and other raptors, especially when they are located near good prey populations. It is questionable whether such perches are really significant in the overall survival of the birds. However, they are undoubtedly a real convenience to the birds and would permit them to expend less energy in searching for prey than if they were forced to remain aloft in order to sight potential prey. In one study in Utah by the U.S. Forest Service, artificial perches were erected in mountain meadows to test their use by raptors and to determine any possible benefits they might offer through their use by raptors in controlling pocket gopher populations. It was concluded that, while there was significant reduction of pocket gophers near the hunting perches, the total impact of raptor predation on the gopher population was not clear and required further study.

The development of reliable methods of assessing prey species habitat or populations is a necessary prerequisite to raptor population manipulation (Fyfe and Armbruster, 1977). One technique for assessing prey populations has been simply to carry out population surveys of prey species in association with current and previous nest sites, thereby permitting comparison of the relative abundance of prey species. Another approach has been an evaluation of habitat use by prey species or, in the Canadian prairie region, to assess the influence of land use practices on prey abundance and on raptor population density and productivity (Owens and Myers, 1973; Hodson, 1975).

\section{Acquisition of Crucial Raptor Habitats}

Preservation of sufficient habitat in undegraded condition is a critical necessity for a number of species of raptors having specific habitat requirements (Snyder and Snyder, 1975). While there are many areas of public lands that are highly important to raptors and-may be managed for their preservation at the discretion of the administering agency, there are many other crucial areas that are under private ownership. Individual owners may or may not have empathy for the birds of prey or other fauna on their lands. For long-term effectiveness in providing protection to declining raptor populations or for the peripheral species of the Southwest, it would be advantageous to either (1) bring the required land acreages into public ownership by Federal purchase or land exchange, (2) transfer ownership to private conservation organizations through direct purchase, (3) acquire ownership through purchase by the state 
wildlife agency, or (4) enter into a cooperative agreement with the private landowner to provide adequate undisturbed habitat to assure the perpetuation of the selected raptors.

Where large tracts of land in private ownership have significant raptor use, it is entirely possible that private organizations will achieve greater success than government agencies in persuading business or industry representatives to adopt management procedures designed to protect the resident raptors (Murphy, 1978). Many raptor species do not seem to be flexible in changing their habitat preferences in the face of intensive real estate developments or other land uses. For such species, only the preservation of relatively undisturbed or unmodified tracts of land will provide a degree of assurance that those species will be maintained as viable populations. Examples of human encroachment into raptor habitats are: urban sprawl in the Phoenix area (causing displacement of Harris' hawks (Parabuteo unicinctus); construction of summer homes, ranch homes etc., at the bases of cliffs throughout the West, producing unacceptable disturbance to golden eagles, prairie falcons, and other species that may have nested in the cliffs for generations; or development of oil and gas or coal mining facilities in good nesting canyons with the subsequent elimination of large nesting raptors that will not tolerate the noise and human activities. As emphasized in previous sections, priorities in raptor management should be to (1) identify through surveys the most important habitats for each raptor species, (2) identify the management objectives for each species, and (3) develop the procedures necessary to accomplish the objectives. Since we must assume that present and future human demands for natural resources will preclude the preservation of all existing raptor use areas, we must first identify the most important habitats and then direct our energies to preserving the habitats having greatest significance in the preservation of the species. Secondary efforts may be provided to mitigate impacts on areas of lesser importance.

Management of Historical Raptor Eyries

Resource managers are aware of many historical eyries (some active and some not) of several species. An example of historical eyries are those of peregrine falcons along the Wasatch Front in Utah that are no longer active but which were used for decades prior to the decline of the birds during the DDT era. Specific sites are selected by raptors for nesting because of some special characteristics of those sites that fill specific needs of the birds. Most birds act as if they were programmed to behave within certain limitations, whether it be for nesting, feeding, or in meeting other physiological or psychological needs. Nest site selection is the expression of one of these innate behavioral patterns. The fact that a specific kind of site and location is selected is good indication that the site meets the birds' requirements. Sometimes in the first nesting attempt, young birds will select sites that seem to be somewhat marginal based on the usual pattern for the species. This may be because the more desirable sites are already occupied by 
established pairs, or the process may be partially a learning experience for new nesters. In any case, the protection and maintenance of inhabited or utilized sites must be given much higher consideration than setting aside areas for use by raptors based on human judgments of desirability, especially where such areas may not have demonstrated much active raptor use in past years.

Investigations are presently underway by the U.S. Fish and Wildlife Service to determine the feasibility of relocating golden eagle nests. This is being accomplished under the direction of the Denver Research Center to determine if golden eagle nests removed from proposed coal mining sites and re-situated on adjacent cliffs will be accepted and used by the displaced birds. In the author's opinion, if a golden eagle nest is destroyed (after the nesting period) by a coal mining operation or other land use, and there are other undisturbed and suitable nesting sites within the pair's territory, they will quite likely move to such sites in subsequent years and construct a new nest. Actually, most golden eagles have alternate nests already constructed within their territories and will simply switch to one of these alternates in subsequent years if their current, active nest is destroyed. The success in acceptance of translocated nests should be tested, but the actual need for such actions may remain questionable.

Complete protection of nests and adjacent areas (variable, depending on situation) of threatened or endangered species should be provided. Because of the very real possibility of creating further declines in endangered species' numbers by trying to accommodate a variety of land uses in proximity to the nest site, only those uses that are known to be acceptable to the birds, such as livestock grazing, should be authorized. Testing of behavioral responses to various disturbances should be restricted to species with healthy populations. For example, research on golden eagles is acceptable because the population seems to be doing well throughout most of the West (author's opinion).

\section{Restrictions on Human Use of Raptor Nesting/Roosting Areas}

Shooting Prohibitions--In general, the impact of shooting appears to increase with the size of the raptor, probably because of the conspicuousness of large raptors (Snyder and Snyder, 1975, from Brown, 1974). Glue (1971) stated that diurnal raptors seem to suffer more loss than nocturnal ones. Despite legal protection in most states and total Federal protection, shooting of raptors still continues. This is indicated by the fact that most band returns for diurnal raptors are reported as shot. Studies by Henny and Wight (1970) indicate that redtailed hawks and Cooper's hawks both suffered considerable mortality from shooting. Mortality from this cause was estimated to be from 12 to 24 percent for these two species during the period from 1946 to 1957. The estimated shooting mortality was sufficiently high to make Henny and Wight (1970) believe that the population decline in Cooper's hawks reported by Bent (1937) in the early part of this century was largely 
by shooting. Shor (1970) estimated that over half the first-year peregrines wintering on the Texas coast end up shot. Scientific collecting probably caused an overwhelming stress on populations of the California condor around the turn of the century, causing a possible irreversible trend in their population.

Most raptors are highly vulnerable to shooting when perched on power poles, and there is evidence to indicate that large numbers are still being killed for "sport" throughout the West. Several additional citations are given by Snyder and Snyder (1975) to substantiate this.

Because raptors are frequently shot by persons seeking unusual targets, it may be necessary to close some public land areas to firearms. This has already been initiated in the Snake River Birds of Prey Natural Area in Idaho during the nesting season and in the Aravaipa Canyon Primitive area in Arizona, two areas of BLM administration. Present disregard for laws protecting raptors from shooting suggest that more stringent laws would accomplish very little unless greatly expanded enforcement and education were implemented simultaneously (Snyder and Snyder, 1975). Complete protection of raptors from shooting verges on the impossible because of vast acreages of public lands and the large areas of responsibility for each enforcement agent. However, firearms closure does reduce the use of firearms in such areas and should be considered for any raptor concentration areas or in areas where peripheral, endangered, threatened, or seriously declining populations occur.

A variety of factors cause mortality in raptors, so it is usually difficult to determine what percent of the total mortality is caused by shooting. However, studies such as those by Ellis et al. (1969) indicate that in some situations shooting of birds of prey is very high. In a year and a half study, Ellis et al. found an average of 3.14 dead raptors per mile along a $12.1-$ mile road paralleling a power line in Utah. The dead birds were primarily golden eagles but also included bald eagles, buteos, and other species. They believed that most of this mortality had been caused by shooting and emphasized the high vulnerability of raptors on utility poles that parallel roads. The number of dead birds found was highest in fall and winter, at which time the greatest amount of sport hunting for rabbits occurs. It is likely that many of the raptors were shot as additional targets by rabbit hunters who had no empathy for the birds. The number of dead raptors found that may have been attributed to electrocution by the power lines was not documented, but most mortality was believed to have occurred from shooting.

Land management considerations that might reduce the amount of shooting of raptors on power poles would include the following: (1) siting power lines away from highways and other roads, (2) prohibiting road construction adjacent to power lines, (3) shifting to underground power cables where feasible, and (4) increasing public education programs to enlighten the public on the esthetic, scientific, ecologic, and economic values of birds of prey. 
Restrictions on Rock Climbing--Mountain (or rock) climbing has become a popular sport throughout many parts of the country, particularly in the West. Unfortunately, many of the better cliffs for climbing are also some of the better nesting sites for golden eagles, peregrine and prairie falcons, red-tailed hawks, or other raptors. Most climbers are interested primarily in the challenge of the climb (or descent) and have no intention of causing any problems with nesting birds. Others will recognize the presence of the nest of an eagle or other large raptor and will climb into the nest just because of the increased attraction it offers during the climb (or descent).

Military units of various kinds include rock climbing training for selected personnel. High cliffs are their specialty and many instances are known where descents were made during the course of a day or for several days in the vicinity of eagle and falcon eyries. The timing of such training and of individaul activities may be critical to the birds. In general, rock climbing at cliffs containing nests should not be allowed at the time when the birds are on eggs and should be permitted no closer than $\frac{1}{2}$ mile to nests containing young. Such activities normally involve various amounts of shouting or other noise which will be sufficiently disturbing to the birds to keep them away from their nests if the activity occurs close by. The young birds may miss important feedings or may be subjected to intolerable heat or cold in the absence of brooding.

Cliffs containing several nests of various species of raptors or of the same species should be closed to rock climbing during the nesting season, generally from February 1 through August 1. This is especially true for any cliffs containing eyries of bald eagles (in Arizona), peregrine falcons, or California condors. A single nest of any of the endangered species will justify cliff closure to any human activities.

Restrictions on Recreation Uses--Unfortunately, many areas preferred by humans for recreation are areas that coincide with raptor preferences for nesting sites. This is especially true of riparian zones, since water-based recreation sites are at a premium, especially throughout much of the Southwest, and they are becoming more popular each year. Consequently, people congregate at such areas in spring and early summer at the time when black hawks, zone-tailed hawks, gray hawks, and other raptors are laying eggs and beginning to incubate. This is the worst possible time for disturbance to the birds, and many of them fail to bring off a brood because of frequent disturbances near their nest sites. Dr. Jay Schnell (1979) of Klondike, Arizona, has been studying the ecology of the black hawks in Aravaipa Canyon in Arizona for several years and has observed the abandonment and/or disruption of nesting activities on several occasions. Re-nesting attempts also frequently fail due to hikers, backpackers, and campers using this highly scenic area. BLM has recently placed restrictions on human use in the canyon to preclude some of this disturbance during critical periods. Increasing 
numbers of recreation sites are being developed along river canyons of the West to accommodate the increasing numbers of vacationers. Each new development creates some additional stress on the wild creatures of the area. While some forms of wildlife can adapt to human activities, many cannot.

Throughout the West and Southwest, canyons containing running water serve as cool camping and picnicking areas. Such canyons may also provide the best cliffs or trees for raptor nesting in the entire area, and conflicts between humans and birds are inevitable.

Many benefits to the raptors could be achieved if trails, campgrounds, interpretive sites, rest areas, etc., were sited in areas that had no special attraction to the birds for nesting, roosting, or feeding. The other possibility is to restrict human activities in such areas until after mid-summer. This would permit the birds to complete their nesting activities without undue disturbance from humans and their accompanying pets and vehicles.

Off-road vehicles continue to create concern over their effects on wildlife. Occasional and irregular ORV traffic appears to have less effect on terrestrial mammals and reptiles than on raptors. Many bird biologists believe that the nesting period is the most crucial time in the birds' annual cycle. This is a time when the birds are already under considerable physiological stress and of ten cannot stand the stresses created by recreating humans. While human activities in winter may create many kinds of disturbances, the birds at this time are not tied to specific geographical areas and can move to other areas with little apparent stress. While snowmobiling, skiing, pipeline construction, and other activities may cause the birds to change locations, it does not usually cause any significant mortality. The reader may cite instances where habitat needs, other than for nesting, may be crucial in the life cycle of raptors, but the nesting period continues to be the most crucial for most species as far as annual needs are concerned. It is likely that problems will continue to worsen unless land managers recognize the threat of off-road vehicles to certain forms of wildlife and take the necessary steps to protect the more sensitive species from disturbances at the most critical periods of their life cycles. This can best be done by restricting certain forms of human activities during the critical nesting periods for the species concerned. Such protection may also be needed in selected roosting and feeding sites. It should be reiterated that species behavior in the face of human disturbances is the most important consideration in deciding which land use activities may be tolerated and those which cannot.

Where deemed appropriate for the protection of threatened or sensitive species, landowners may be approached and their assistance solicited in preventing disturbance to nesting raptors on their private lands. Indeed, protection provided by the closure of private lands to public use is almost as good as established sanctuaries in some parts of the 
West. Development of empathy for raptors by landowners is very important for species such as the gray hawk that nest mostly (if not entirely) on private lands in southern Arizona.

Restrictions on Low-Flying Aircraft--White and Sherrod (1973) indicated in their paper for Alaska that gyrfalcons (Falco msticolis), peregrine falcons, and rough-legged hawks are generally not greatly affected by low-flying helicopters or fixed-wing aircraft. However, the amount of disturbance will be governed partly by the amount of hovering time over the nest or the number of close passes made by the aircraft. White and Sherrod mentioned that falcons and eagles will sometimes attack aircraft that are hovering or flying close to their nest. This can be dangerous to both the birds and the aircraft occupants if they should come together in an inappropriate manner.

In his years of aerial surveys the author does not know of any nests of eagles, falcons, or buteos that were abandoned because of his aerial survey activities, but his flying was done mostly with fixed-wing aircraft of the Cessna 172, 180, and 182 types. The usual precautions must be taken when using aircraft as when doing surveys from the ground, i.e., (1) do not keep the adults away from the nests any longer than absolutely necessary to accomplish the research or survey; and (2) do not hover over nests during periods of cold, heat, or moisture when the young birds would be unduly exposed to the elements.

\section{Discretion in Raptor Surveys and Research Activities--Conservation} groups and private individuals sometimes accuse raptor researchers of causing the mortality of young birds during the course of their investigations. It must be acknowledged that some mortality is caused usually because of inexperience with raptors by new researchers, but sometimes even by experienced personnel due to unusual circumstances or extreme sensitivity of the adults. Because of the amount of knowledge now available on raptor behavior and essential precautions to be exercised in the conduct of raptor investigations, there is probably much less mortality of eggs or young caused now than there was 15 to 20 years ago.

Whenever new personnel are sent into the field to conduct surveys or research, they should be thoroughly apprised of the precautions that need to be taken. These are thoroughly discussed in Fyfe and Olendorff (1976) and in Call (1978). Those who are engaged in the business of preserving the nation's birds of prey and who periodically conduct various kinds of research to obtain needed management information should be those who will be the most careful in their conduct while in close proximity to the nests they are studying. Needless mortality should be avoided to the maximum extent possible. Most persons become biologists because they enjoy observing or handling wild animals, but this enthusiasm must always be tempered by wisdom and caution if handling birds or even closely approaching the nest. It may cause the death of the very animals we are seeking to preseme. Before anyone undertakes research or surveys on selected species, they should become thoroughly knowledgeable on the behavioral characteristics of those species. 
Raptor surveys are being conducted throughout the West (and throughout the nation) in order to obtain needed information for land use decisions. Sometimes more than one agency becomes involved in collecting information on birds of prey in contiguous or even the same areas. Double or triple disturbance of the birds is sometimes caused by these overlapping survey activities. AlZ survey and research activities should be coordinated with all agencies or groups that may be interested in the same species in the same area. If the state wildlife agency is planning to conduct a survey of raptors in a specific area; BLM, USFS, or other agencies may cooperate but should not duplicate the work. By combining money, manpower, and expertise, a more efficient job can be accomplished, and usually a larger area surveyed. Do not be afraid to take the initiative in coordinating work between conservation agencies or private conservation groups. It will pay off in the long run! 


\section{HABITAT DEVELOPMENT FOR RAPTORS}

Biologists recognize that there has been a progressive loss of suitable habitat for many species of raptors. In view of this we should keep in mind the statement by Snyder and Snyder (1975): "No species (of raptor) can sumive in the wild without adequate acreages of habitat to which it is adapted, and thus safeguarding habitat is the primary necessity in preventing the loss of species and in maintaining the numbers of raptors at desirable Zevels." The maintenance of suitable natural habitat for the various wildlife species must be our primary objective. While artificial habitats such as artificial nesting platforms can serve to supplement nesting sites for populations in areas where natural nesting substrates are very limited, they should not be considered as a panacea to our habitat management problems. Artificial stmuctures should be used with discretion after management objectives for the area have been established and should be made to look as natural as possible. They are frequently useful in maintaining raptor populations in areas where natural nest sites are being gradually destroyed or made unacceptable by nearby activities of man or in building populations where all other life requirements are available except suitable nesting sites. But...first consideration should be to maintain as nearly a natural environment as possible.

In areas where raptor populations are gradually increasing, some birds may be forced to nest in substandard sites. In such situations, either the eggs or young may be in jeopardy from numerous mortality agents throughout the nesting period; thus, artificial nesting structures in good sites may increase chances for survival.

\section{$\underline{\text { Artificial Nesting Structures }}$}

There are many examples of successes in the use of artificial nesting structures. Raptor biologists all across the country are trying various modifications of proven designs and achieving varying degrees of success. This paper will present only a few representative examples.

Hamerstrom et al. (1973) demonstrated that kestrels could be substantially increased by the construction and placement of nest boxes in areas where lack of suitable nesting sites was the primary population limiting factor. The Susanville, California, District of the Bureau of Land Management has had a similar response from kestrels from the placement of 100 nesting boxes in juniper trees. Good results were also obtained by Woyda and Martin (1977) in Cache Valley, Utah. Fyfe (1979, personal commun.) has had excellent success in acceptance of artificial cavities by prairie falcons in Canada and in acceptance of artificial nest structures by ferruginous hawks. Anderson (1979, personal commun.) has had excellent success in acceptance of both modified and completely artificial nest structures by ferruginous hawks in Colorado, and Howard (personal commun.) has had similar experiences in Idaho. Two of three 
artificial nest structures initiated by the author in 1979 on the Pawnee National Grasslands in Colorado were utilized the same year by ferruginous hawks. Postupalsky and Stackpole (1974) increased a population of ospreys at a reservoir site in Michigan through provision of artificial nesting platforms. Artificial nest sites for ospreys have also been tried with some success in California (Garber et al., 1974), Oregon (Neitro, 1978, personal commun.), and on Chesapeake Bay (Reese, 1970). Artificial nest structures for everglade kites (Rostrhamus sociabilis) in Florida also apparently have proved to be of value (Sykes and Chandler, 1974).

Owls do not construct their own nests and the use of any suitable nests by the various owl species is well known. Virtually any type of artificial nesting structure is acceptable to great horned owls, and other species, including great gray owls, will also use them. One design for artificial nests for great horned owls has been published by Bohm (1977).

Attracting bald eagles to artificial nesting structures is apparently not so easy, but both Postupalsky (1977) and Grubb (1979, personal commun.) have had bald eagles accept and lay eggs and/or raise young on artificial nest structures. Bald eagles accepted an artificial nest constructed by Dunstan and Borth (1970) and laid two eggs but were unsuccessful in fledging any young. Following are some examples of designs that have been successfully used in attracting various species of raptors to artificial nesting sites.

\section{Construction of Artificial Nesting Structures}

Descriptions of methods that may be used to attract raptors to artificial nest sites will be discussed under the following headings: (1) cliffnesting species, (2) tree-nesting species, (3) cavity-nesting species, and (4) species nesting underground. Several species nest in a variety of locations and no attempt will be made to include all possibilities.

Cliff-Nesting Species--Birds of prey that normally nest in cavities or on ledges of cliffs include the golden eagle, peregrine falcon, prairie falcon, kestrel, gyrfalcon, red-tailed hawk, California condor, great horned owl, barn owl (Tyto $a$ lba), bald eagle (in Alaska and sometimes in Arizona), turkey vulture (Cathartes aura), zone-tailed hawk, and osprey.

Creation of cavities or ledges in cliffs, especially in the lower portions of mountain ranges, is a good method for creating additional nesting sites for a variety of species. In this context the author also includes high dirt or clay banks. While golden eagles and other raptors may be found nesting anywhere from the top to the bottom of a cliff, they seem to prefer to nest from about one-half to about four-fifths of the way to the top. A good rule to follow would be to construct the cavity at least one-half of the way to the top, with an assortment of 
different cavities being constructed, if time and manpower permit. The size of the cavity or ledge needed will vary with the species of raptor, and a general rule would be to construct the cavity to permit adequate room for the birds to exercise their wings without excessive contact with either the sides or top of the cavity.

It is not uncommon in the wild to see two of the young birds exercising their wings at the same time, with occasional precarious positioning of one or both birds near the edge of the nest. The author has film of a young golden eagle that apparently lost its balance while exercising its wings, fell over the edge, and remained attached to the nest with only one foot. Fortunately, the bird was capable of flapping its wings and pulling itself back onto the nest.

Nest cavities or ledges for golden eagles should be at least 6 feet long, 4 feet deep, and 4 to 6 feet high (Fig. 1,5). Large amounts of nesting material are used by eagles and cavities tend to become filled with debris over the years. Cavities sometimes become so filled with sticks, etc., that the birds can no longer use them. Cleaning out part of the nesting material will prolong the useful life of the eyrie.

The primary idea in cavity or ledge construction is to build it so that the young can have free movement, the adults can land without difficulty, and there will be some degree of permanence to the site.

For the larger falcons, a cavity approximately the length of the wingspread should be satisfactory (Fig. 4). While many biologists have observed successful fledging of young falcons from relatively small cavities, these are probably not optimal sites. There tends to be a lot of trampling of each other and sibling face-swatting during exercising in small cavities.

Considerable work has been done by Fyfe and Arbruster (1975) in constructing cavities for prairie falcons in cliffs that had few or no suitable natural holes. Cliffs were selected on the basis of several criteria including: (a) site location in relation to suitable habitat for prey species; (b) freedom from excessive human activity; (c) a minimum cliff face height of $7 \mathrm{~m}(22 \mathrm{ft})$; (d) a relatively permanent or solid substrate of clay, conglomerate or sandstone; and (e) freedom from excessive erosion, such as serious undercutting and slumping along river channels.

In sites meeting these criteria, cavities were then built having minimum dimensions of $30 \mathrm{~cm}$ (12 in) deep x $60 \mathrm{~cm}$ (24 in) long x $30 \mathrm{~cm}$ (12 in) high. Several digging methods were tried, including the use of dynamite, but digging by hand with a small shovel generally proved more efficient. of interest is the fact that some of these cavities or ledges have been used by Canada geese. 


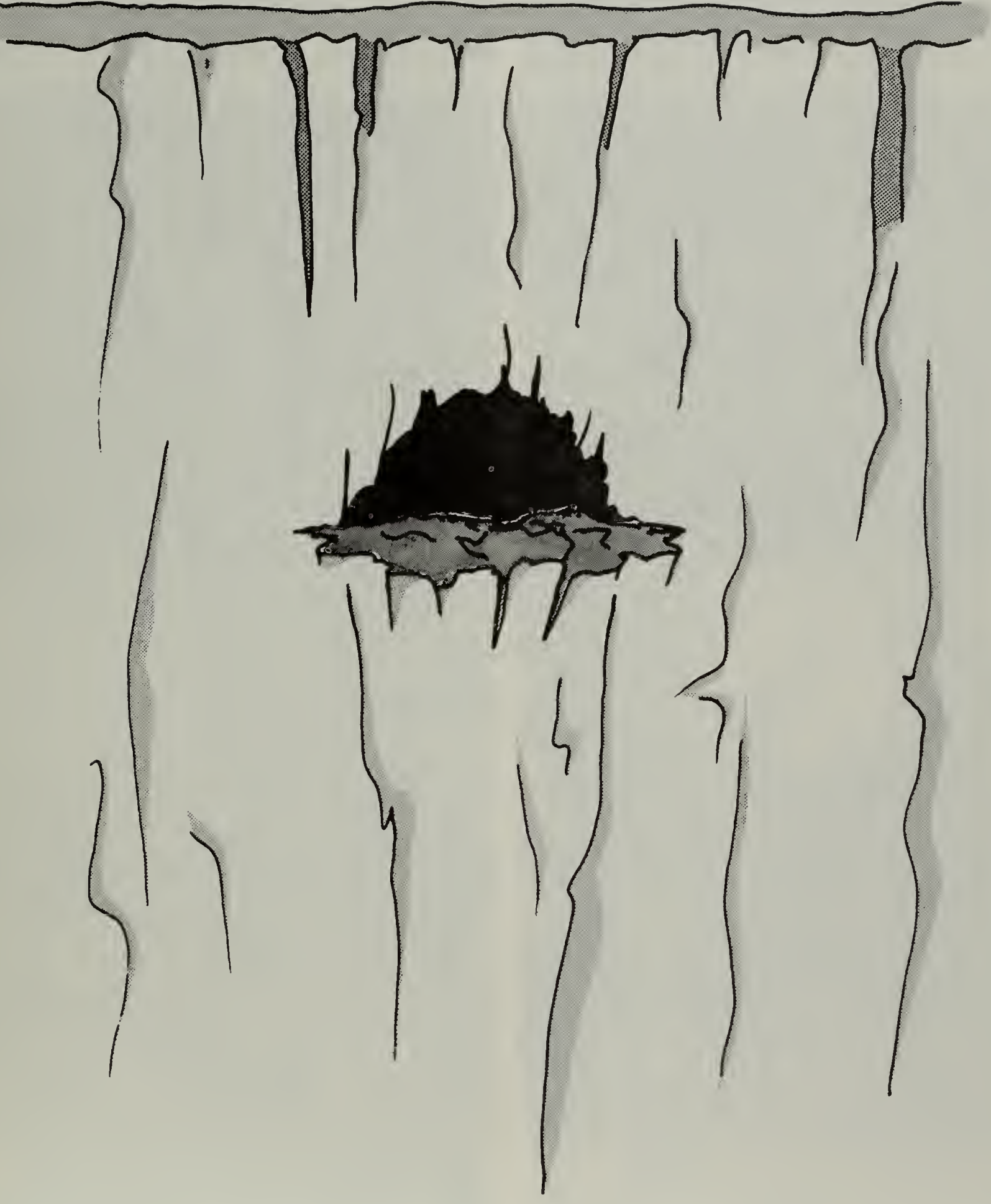

Figure 1. Artist's concept of artificial cavity that could be constructed for golden eagles, red-tailed hawks, or prairie falcons. For golden eagles, cavity or ledge should be approximately $6^{\prime}$ long $\times 6^{\prime}$ high (if a cavity) $x 4^{\prime}$ deep. Prairie falcon cavities should be about $24^{\prime \prime}$ long $x$ 12 " high $x 16$ " deep. 

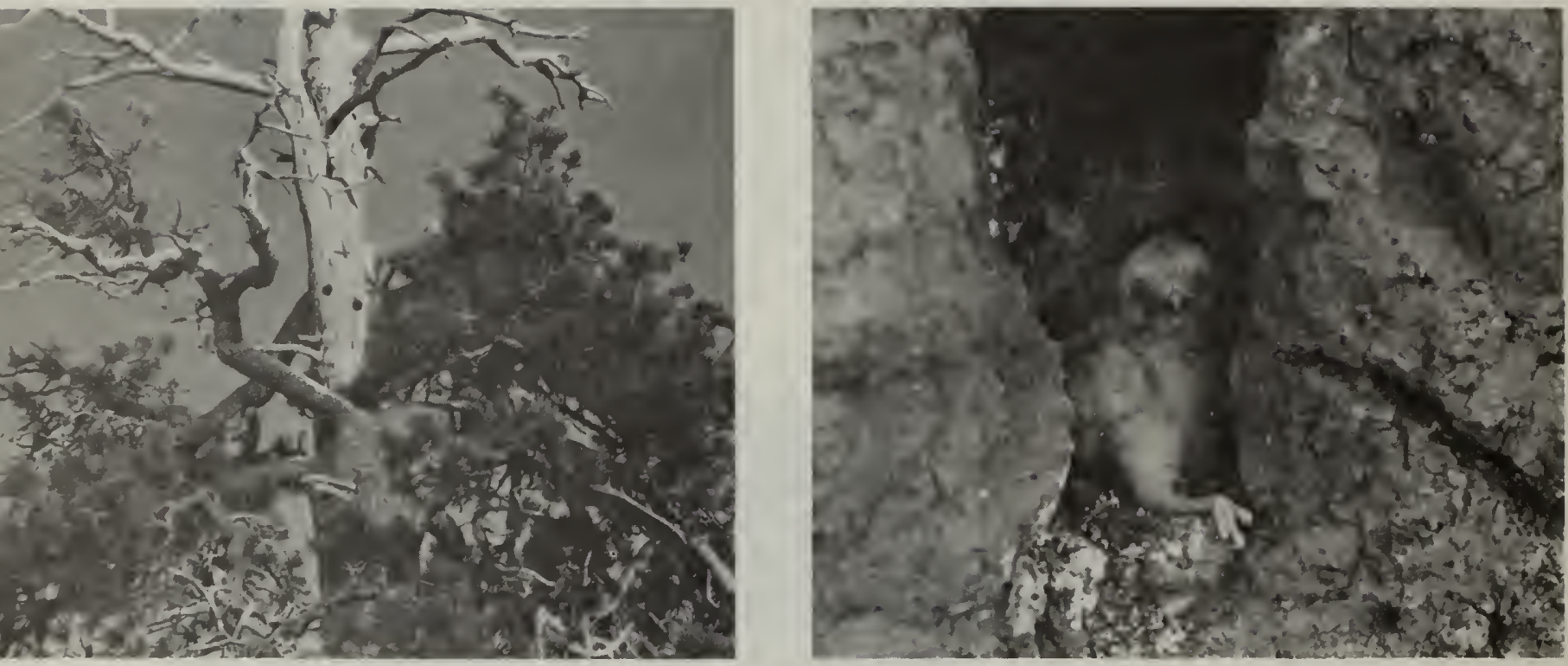

Figure 2. Typical natural nesting sites of kestrels: old flicker nesting cavities, or holes in dirt banks or cliffs.
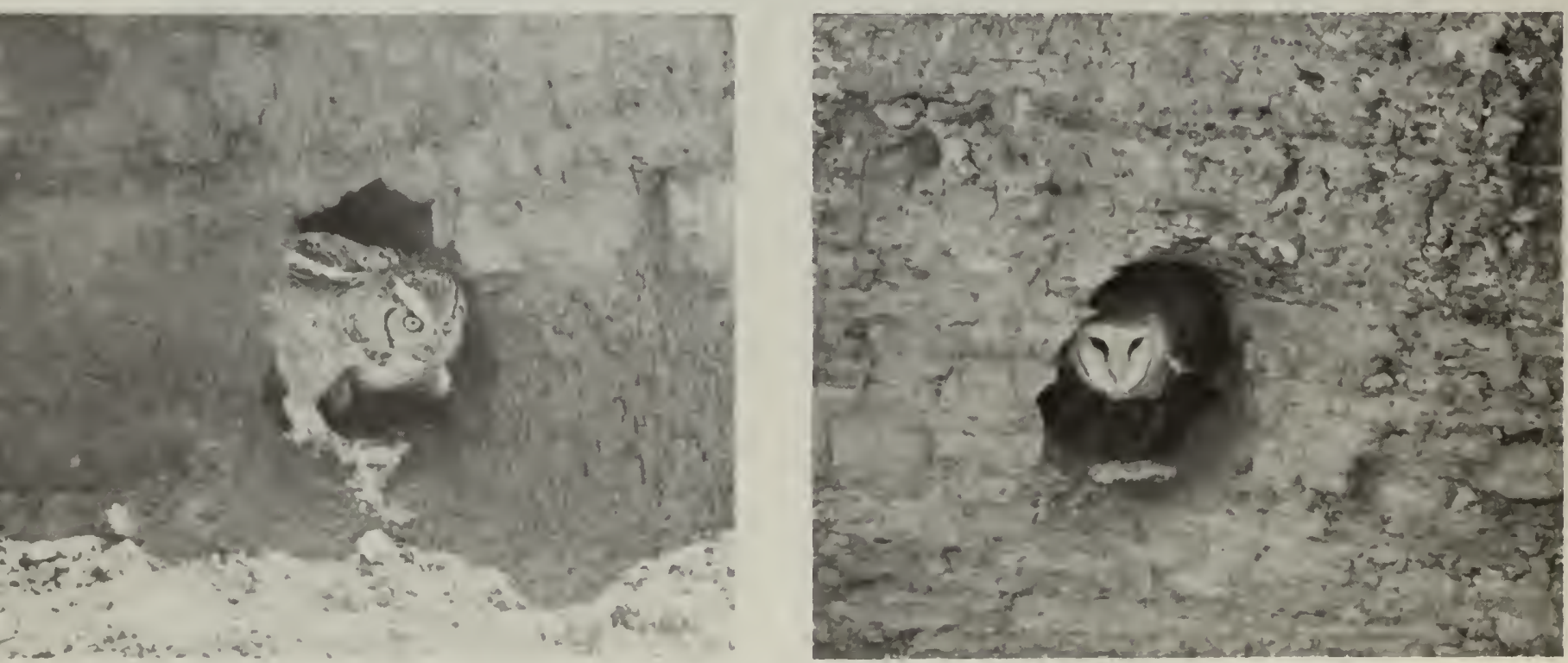

Figure 3. Great horned owls (left) and barn owls (right) often use natural cavities for nesting. 

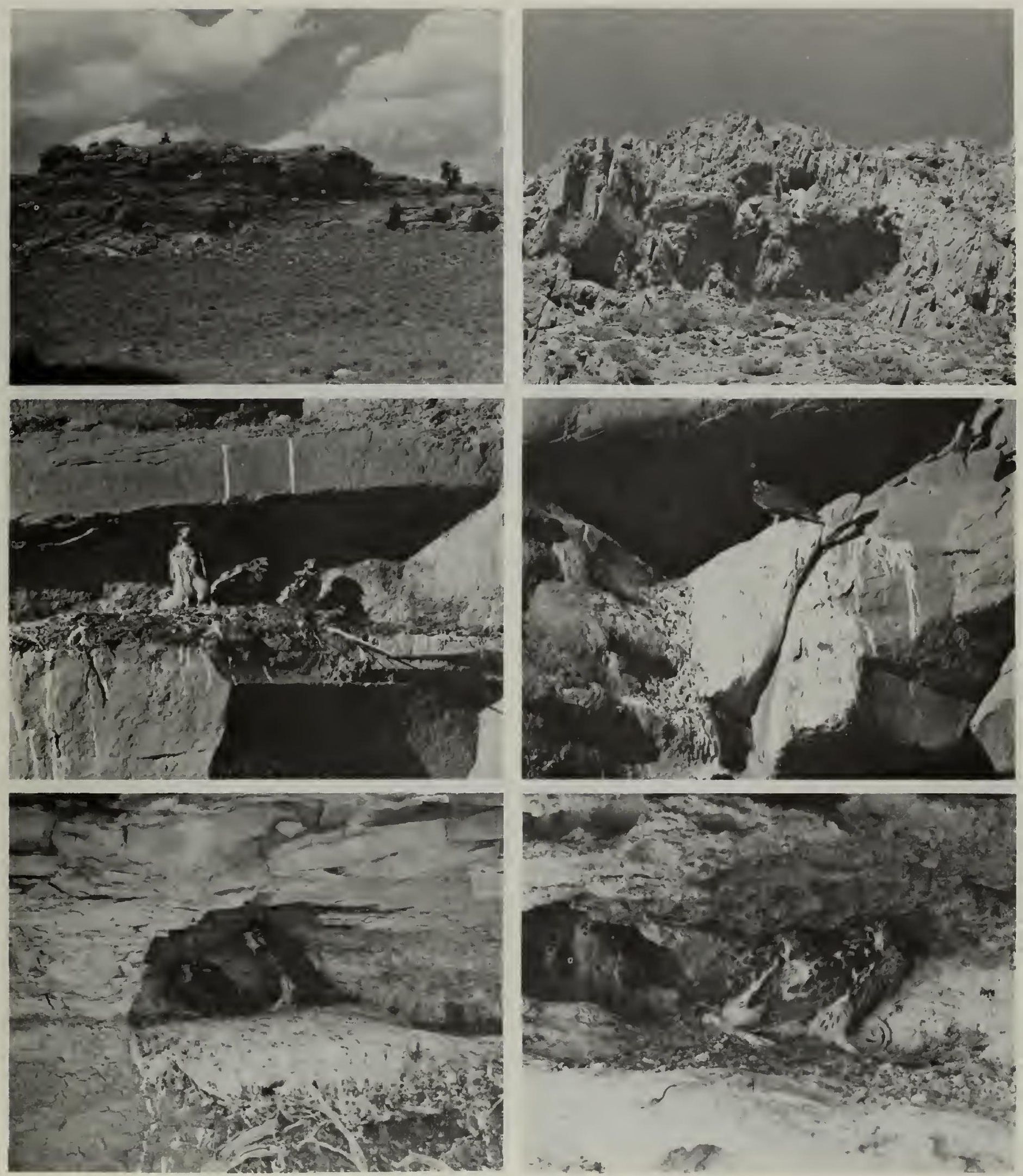

Figure 4. Nesting cavities of prairie falcons showing variety in types of cavities used and locations on cliffs. 
Initial success was encouraging. In 1970, of five nest holes or ledges dug along cliff faces, four were occupied by pairs of prairie falcons and the fifth by a lone male prairie falcon. In 1971, of 12 holes or ledges, eight were used by either falcons or by Canada geese. Since then, the Canadian Wildlife Service field crews and Saskatchewan Falconry Association members have made over 200 nesting holes, and there is occupancy data for about one-fourth of the sites. Since they were dealing primarily with sedimentary materials, there was considerable difficulty with cliff instability, and many of the artificial nest sites eroded or slumped away.

Kestrels use a wide variety of natural cavities for nesting, from flicker holes to eroded holes in trees and dirt banks (Fig. 2). They very commonly nest in cliffs in small potholes or cavities. In areas of the West containing cliffs, there are probably adequate holes to take care of their population's nesting needs and, in such places, no construction is recommended. In areas where kestrels are dependent on cavities in trees, erection of nest boxes may increase the population, as described below.

Red-tailed hawks may nest on practically any projecting ledge on a cliff. If cliffs not having suitable nesting ledges are near good rodent populations, it may be desirable to construct two or three ledges for any of the raptors, including red-tails, that might (and probably will) use them. If cottonwoods or other tall trees or even pinyon or juniper are present in the vicinity of the cliffs, there is probably little justification for constructing cliff sites, since they will nest in trees just as readily (if suitable nest branches are available).

California condor numbers have declined greatly in the past half century, and it is probable that adequate nesting cavities are available for the remaining populations.

Turkey vultures will nest not only in cliff cavities but also under fallen trees, on the ground under trees or bushes, or between boulders. It is not necessary to construct cliff-nesting sites for these birds since potential sites are not limited.

Great horned owls have virtually unlimited nesting sites, since they nest early and have the choice of other raptor nests in their area. They will also nest in many types of cavities in dirt banks, cliffs, broken trees, etc. While artificial nest structures would be accepted by great horned owls, you should give careful consideration to the number of these birds you wish to manage in any given area. They are mortal enemies of prairie and peregrine falcons and sometimes take young of these species from their eyries at night. Inadvertent flushing of great horned owls in daytime may cause their death if large falcons are nearby, as falcons almost always "stoop" on the owls when they are flushed in daytime. Despite their large size, great horned owls seem 
to be doing very well in most areas of the country because of their secretiveness and nocturnal habits. Cavities or ledges constructed for any other species may be used by these owls.

Barn owls nest in cliffs in some regions but also nest in old buildings, processing plants, silos, barns, etc. They are occasionally found roosting or nesting in natural cavities in dirt or shale banks in the Southwest. Where other natural cavities are not available, digging holes in dirt banks may increase the number of these birds nesting in the locality. Holes should be dug at least 6 feet above the ground. In a study by Brian Millsap (1978, personal commun.), 22 nests located in the Fort Collins, Colorado, area were all in clay or dirt banks (Fig. 3 ). Millsap constructed large boxes in 1977 and hung them from high dirt banks in an effort to attract the barn owls to nest in them, but no nesting use has been made of them to date (1979). However, one or two were being used for roosting. In northern Utah where barn owls often use silos for nesting, platforms are being constructed in the upper portions of the silos and are being used for nesting (Wagner, personal commun.).

Bald eagles nesting on cliffs and ledges along coastlines, in Arizona, or in other western states probably have adequate potential nesting sites for reasonable numbers of birds to occupy. Other factors would probably limit nesting density before nesting sites. No situations are presently known by the author that would justify construction of nesting sites for bald eagles in cliffs of the West or Alaska.

Ospreys sometimes nest on seastacks, rocky pinnacles, or projecting structures on cliffs. Since they readily accept elevated nesting structures in trees or on poles, the development of cliff-nesting sites is not recommended. Design of platforms in trees is discussed later.

Because of the limited number of zone-tailed hawks nesting on cliffs in the Southwest, no special site construction is recommended. Most zonetailed hawks nest in trees.

Tree-Nesting Species--Raptors that commonly nest either in trees, high bushes, saguaro cacti, or other high vegetation include bald and golden eagles, all buteos (and other soaring hawks) except the roughlegged hawk in Alaska, all accipiters, merlins (Falco columbarius), ospreys, Audubon's caracara (Polybams cheriway), owls (great horned, great gray, long-eared, barred, spotted, and boreal [Aegolius fumereus]), Mississippi and swallow-tailed kites (Elanoides forficatus), and very rarely, turkey vultures (in the tops of dead trees if cavities are available) (Bent, 1937). Raptors that nest in cavities will be considered in the next section.

In future years students of raptors will undoubtedly try to attract each of the various tree-nesting raptors to one kind of artificial nest site or another. It has already been pointed out that all of the larger owls will accept the nests that are constructed by almost any of the other 
birds of prey, providing they are large enough to provide room for their young (and sometimes when they are not!). For this paper, examples illustrate some types of nesting structures or platforms that have worked in one area or another. The author is unaware of any artificial nesting structures that have been used by merlins, Mississippi or swallowtailed kites, caracaras, vultures, or any of the accipiters.

The most common tree-nesting species that have utilized artificial nesting structures are ferruginous hawks, red-tailed hawks, golden eagles, bald eagles, ospreys, and great horned owls.

Typical tree-nesting sites of ferruginous hawks are shown in Figure 7 , and Figure 8 illustrates the variety of artificial structures that have been tried for ferruginous hawks. Bill Anderson of La Junta, Colorado, while working with Gerald Craig of the Colorado Division of Wildlife, probably has had more experience in attracting ferruginous hawks to artificial nest structures than anyone else in the United States. They plan to publish on their results in the near future.

More often than not, ferruginous hawk nests are less than 15 feet above the ground, often in dead or dying trees. Throughout much of the West, ferruginous hawks nest in juniper trees with the nest being only about 8 to 10 feet above the ground. These birds will continue to use these nests even if the trees die. In Colorado, some nests in dying trees become so heavy that they break their supporting branches and the site is no longer usable. Bill Anderson (1979, personal commun.) is preserving many such nesting sites by either removing the nest, building a supporting structure and then replacing the nest, or by simply building a support under the existing nest. He also "tops" some of these nests to reduce total weight.

Some researchers have tried to attract ferruginous hawks by simply installing some type of pole with a nesting platform at the top, without constructing any semblance of a nest on the platform. My observations and experience indicate that the birds are best attracted to an artificial structure by creating a man-made (ferruginous hawk) nest within the structure. (Even the proper amounts of dried cow manure are properly inserted around the structure!) Sagebrush and other dried sticks can be used for the basic structure, with dried grass, weeds, or leaves being used for the nest cup. Examples of artificial nest structures placed by Richard Howard, U.S. Fish and Wildlife Service, Boise, Idaho, are shown in Figures 9 and 10. Note the sun shades. At least one of his structures has been used by ravens which will nest on a wide variety of man-made structures, either intended or not intended for nesting. Ferruginous hawks seem to accept nest structures very well that are in the range of 8 to 15 feet from the ground. Howard (1979, personal commun.) emphasizes the need to wire some of the major branches into the wire basket to prevent the wind from blowing the nest off. He also recommends that all artificial structures be placed at least $\frac{1}{2}$ mile from any road to reduce potential vandalism. 

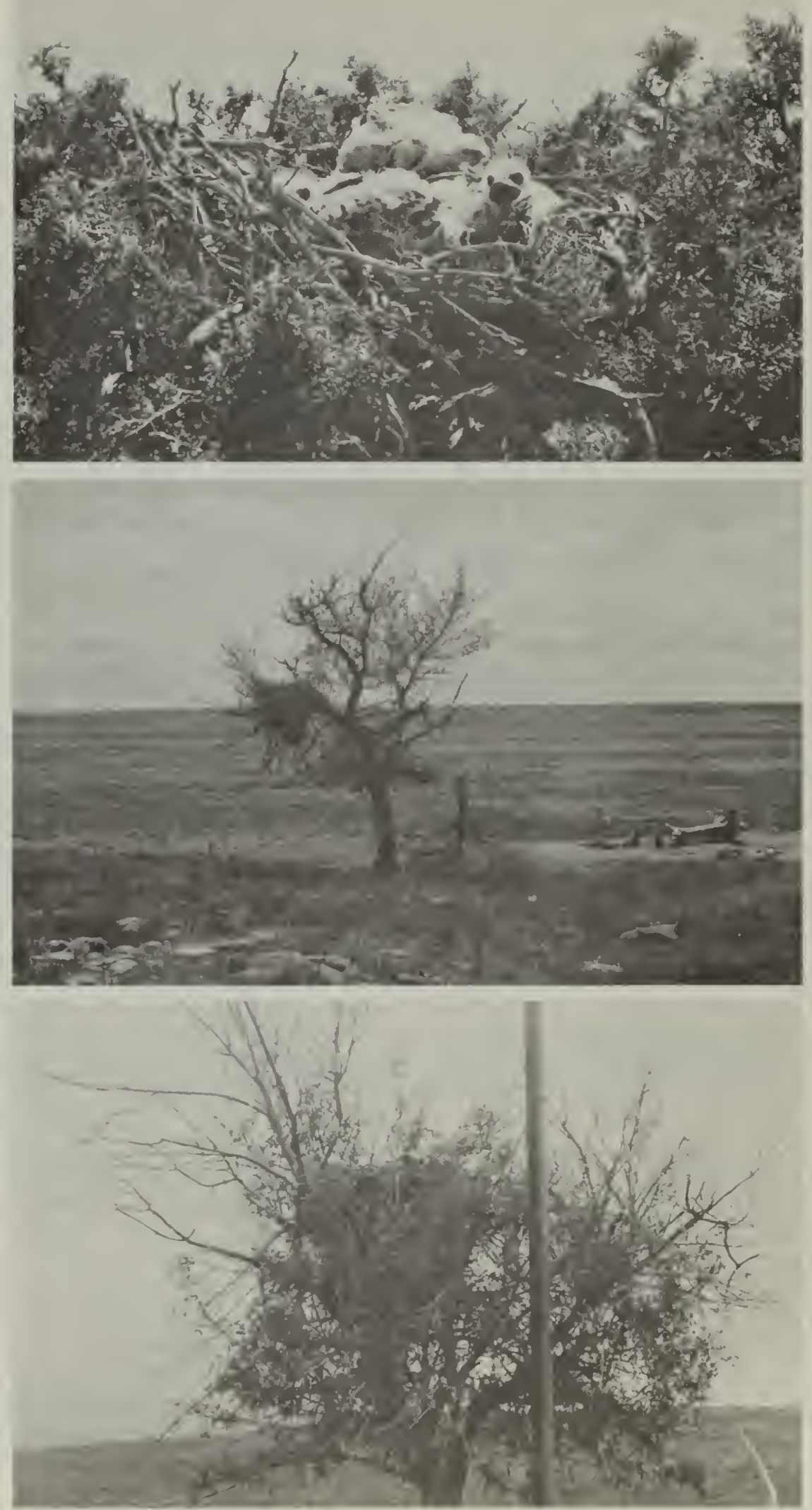

Figure 7. Typical tree nesting sites of ferruginous hawks. 

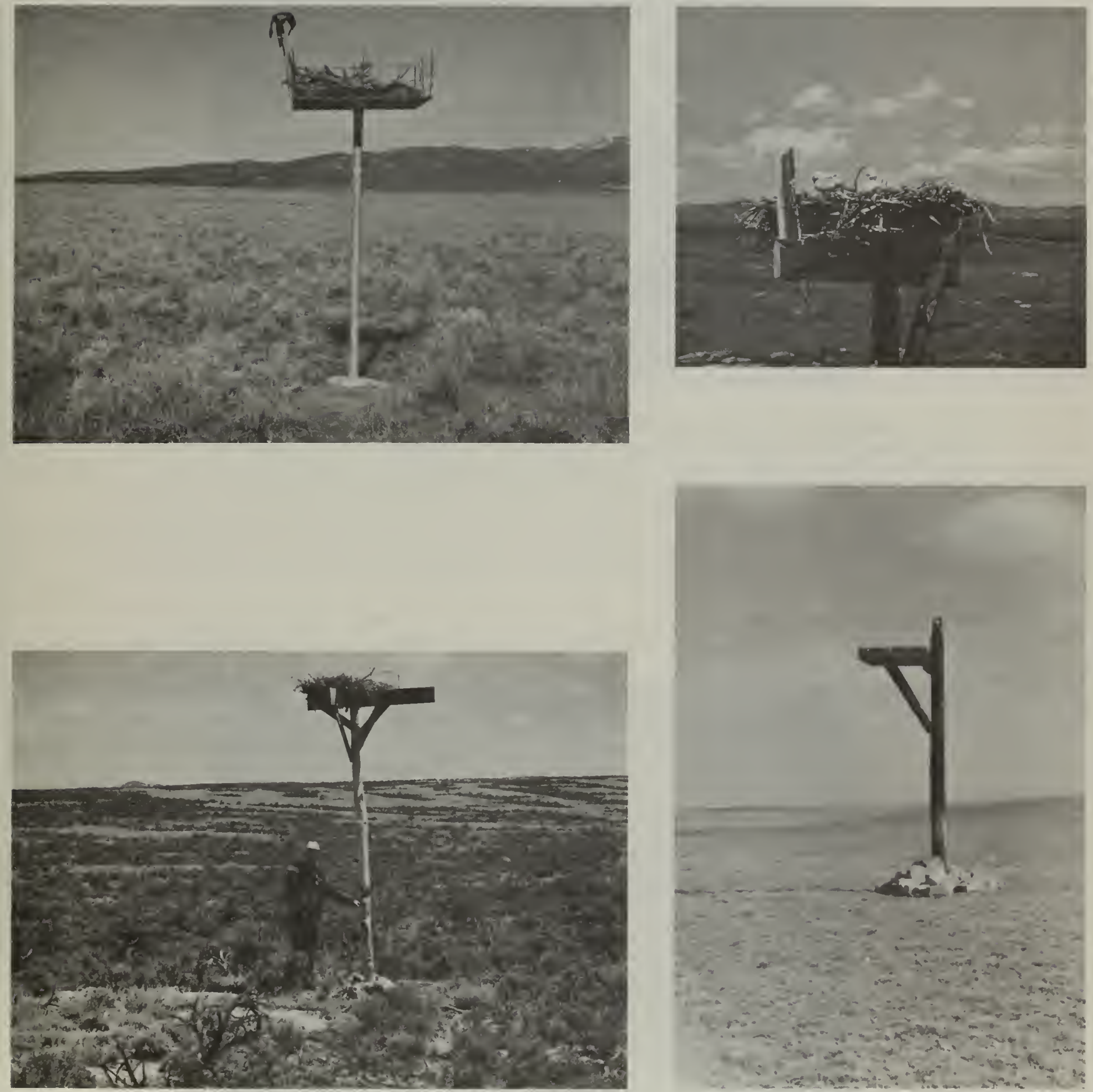

Figure 8. Types of artificial nest structures that have been used to try to attract ferruginous hawks to nest. 


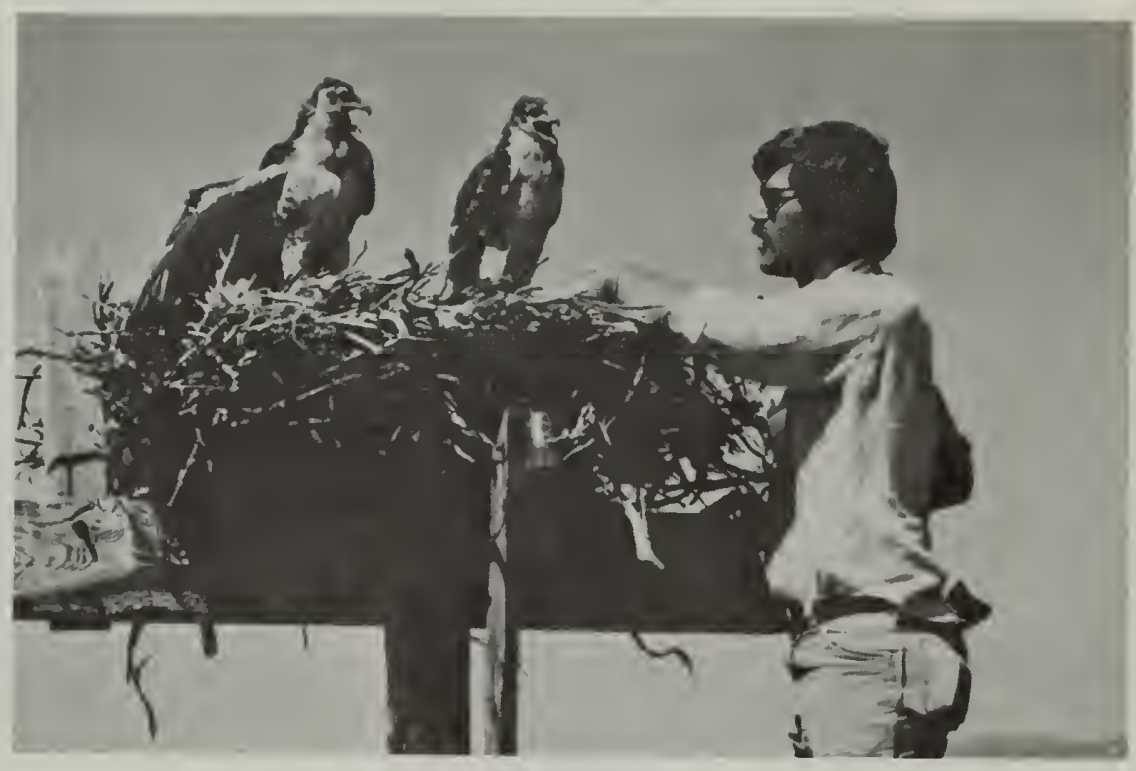

Figure 9. Artificial nest structure occupied by ferruginous hawks near Boise, Idaho.

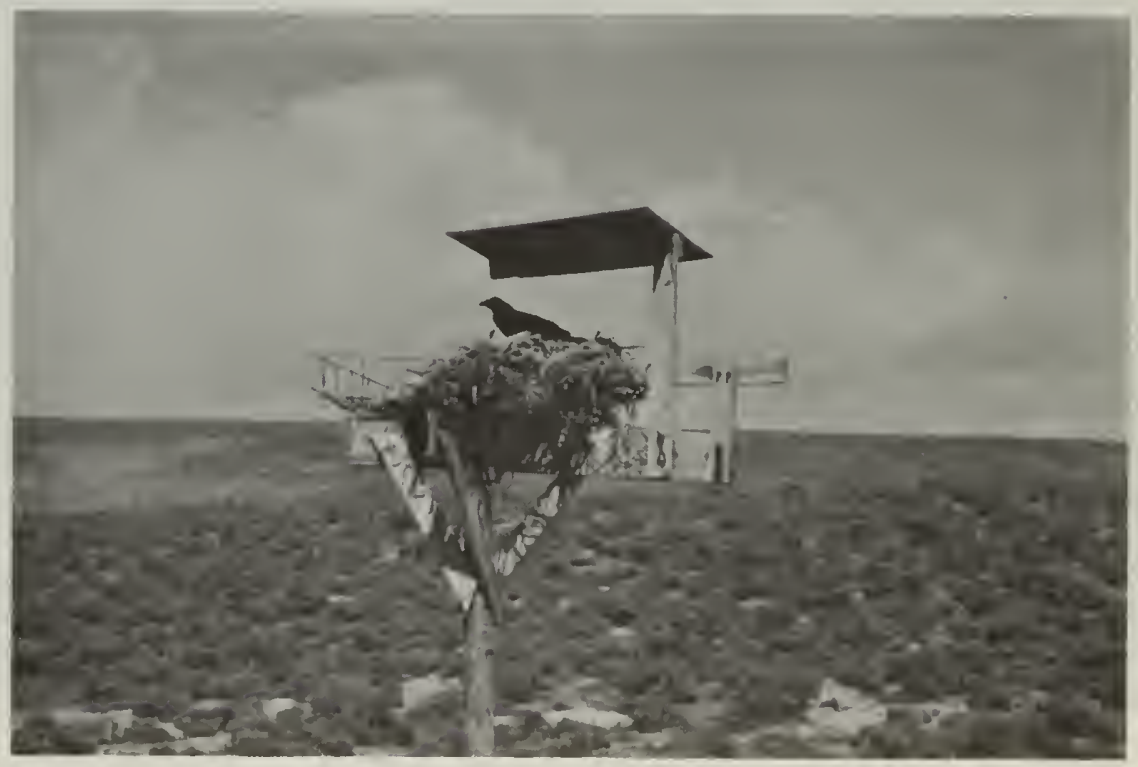

Figure 10. Artificial nest structure occupied by ravens near Boise, Idaho. 
Figures 11 through 14 show a sequence of photos taken by the author during the construction of three wire basket nest sites on the Pawnee National Grasslands during late February and early March of 1979. Ferruginous hawks had used two of these trees for nesting in years past, but the nests had not been active for two years and the original nests had blown down.

Chicken wire mesh was slung between two or three heavy branches and securely tied to them with heavy wire. Wire was also woven through the meshes and then tied to the branches to support the open ends. Wooden debris and heavy branches were used to form a solid bottom to the structure, with additional branches worked into the structure until a semblance of a nest was created. A hollow center portion was formed of smaller branches, leaves, debris, and dried cow manure to provide a nesting cup. The photos in Figure 15 show the finished products. It was found that upon acceptance of such nests ferruginous hawks added very little except some inner lining materials for the nest cup. As usual, however, additional materials were added throughout the nesting period.

On prairies and other shrub-grassland areas where trees are very scarce, the trees are at a premium as nesting sites for raptors. Where nests occur in such trees, it may be advisable to fence livestock away from the tree or group of trees in order to prolong the life of the site. Otherwise, cattle tend to "shade up" under these scattered trees, rubbing the bark and trampling dirt away from the roots until the trees eventually die (Fig. 16; also see Olendorff and Stoddart, 1973).

Ferruginous hawks frequently use the same nest for several years. Many of these nests are in dead trees or on dead branches that will not last long without supplemental support (see Fig. 17). If the tree is fairly solid, the nest may be given greater longevity by providing nest supports only. In some cases, however, the entire tree may need to be braced if the nest is to be saved.

In Alberta, Fyfe (1975) reported that a major limiting factor for some of the buteos appeared to be the lack of trees or elevated areas for stick nests. The ferruginous hawk and some of the other buteos regularly used remnants of old stick nests of crows, magpies, or other buteos as a base upon which to build their nests. Fyfe (1975) first constructed and erected artificial tree nests in 1971 in five areas where old sites had been destroyed. Four of these were occupied in 1972. Since then (by 1975) 37 baskets have been erected, of which 22 were erected in former raptor territories and 15 in grassland areas judged to have adequate prey but with no previous record of occupancy. Of the 37 baskets, a total of 16 had been occupied by 1975, indicating the effectiveness of this technique. The majority of the occupancy was in former territories, indicating that these should receive first priority for artificial nest structures. 


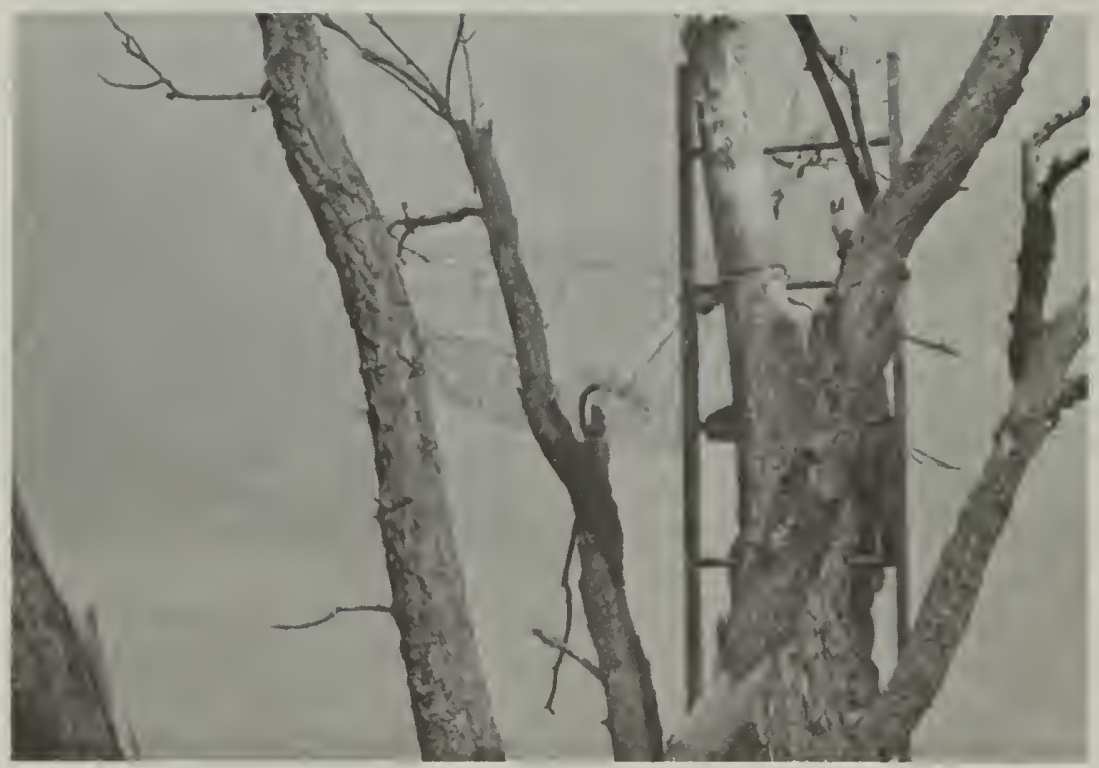

Figure 11. Wire basket nest construction for ferruginous hawks. Chicken wire is being securely tied to branches with heavy wire.

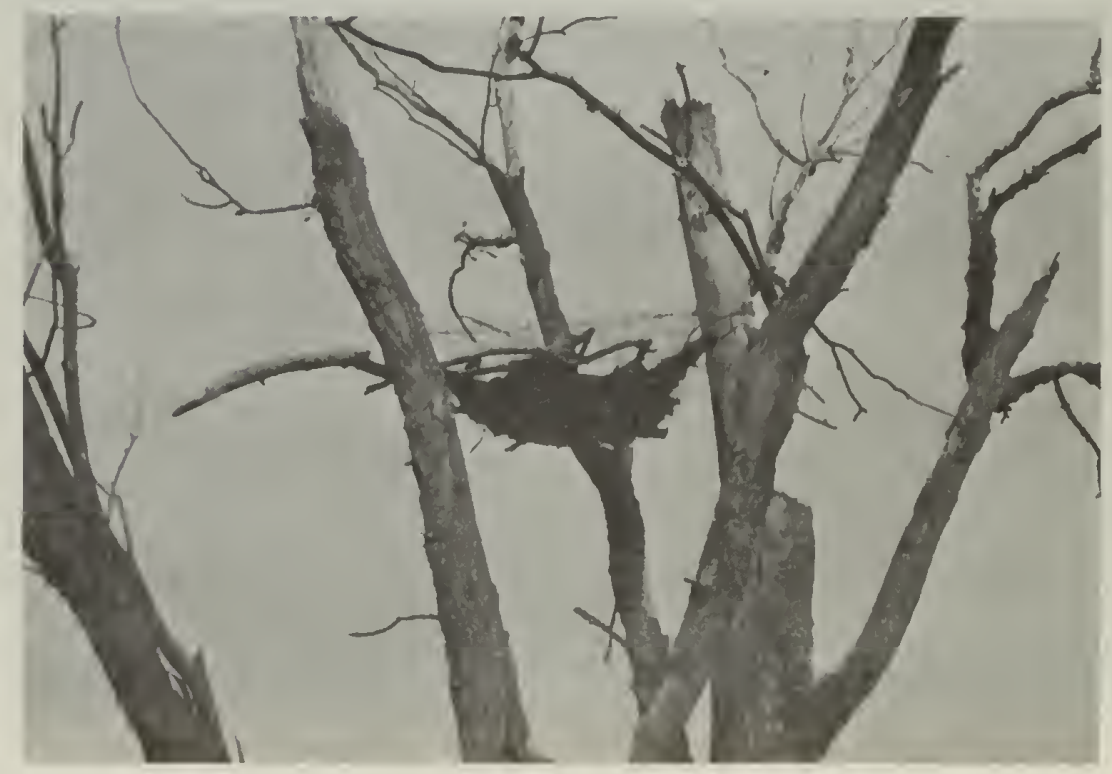

Figure 12. Branches and other material are being placed in chicken wire basket as base for nest. 


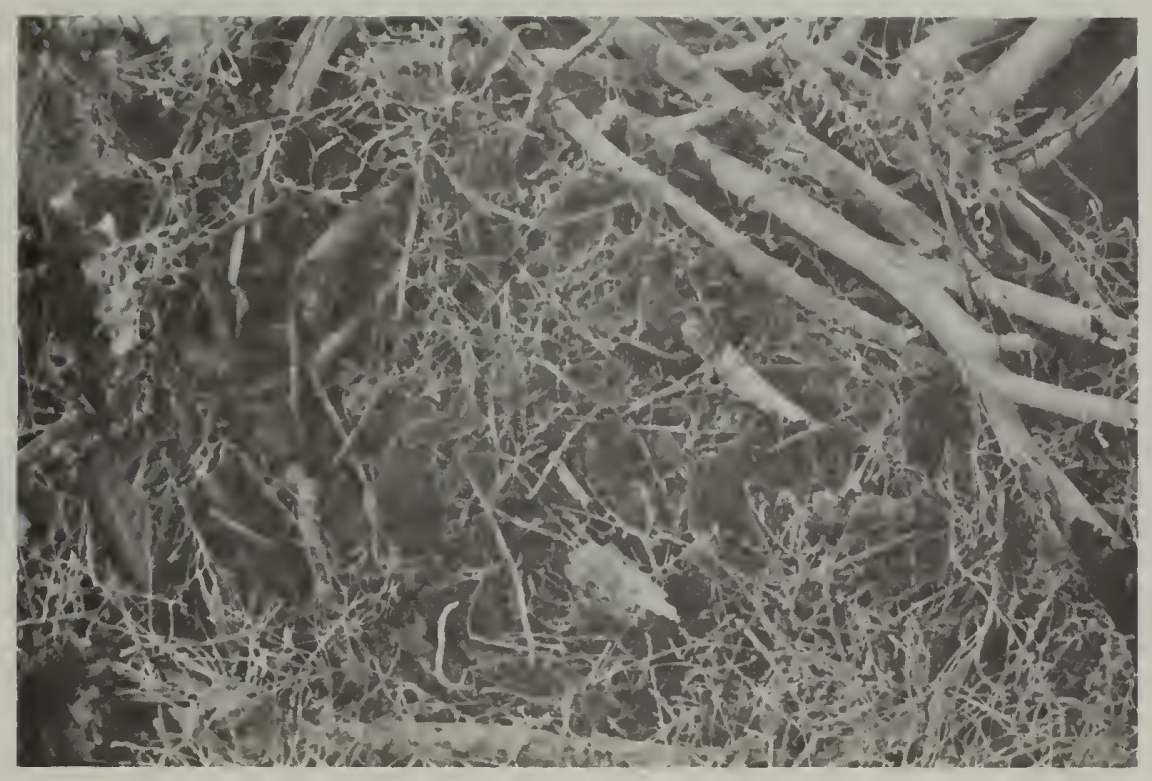

Figure 13. Completed "artificial" nest as it looked immediately after construction.

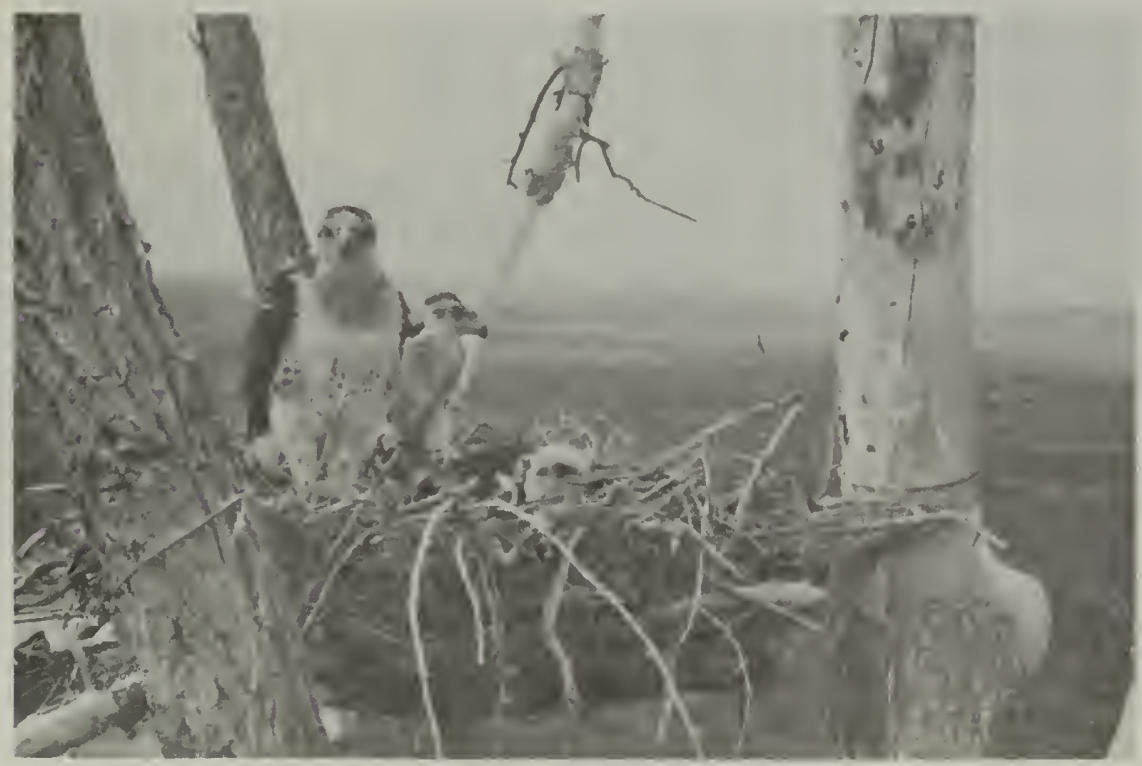

Figure 14. Artificial wire basket nest being utilized by ferruginous hawks the same year it was constructed. 

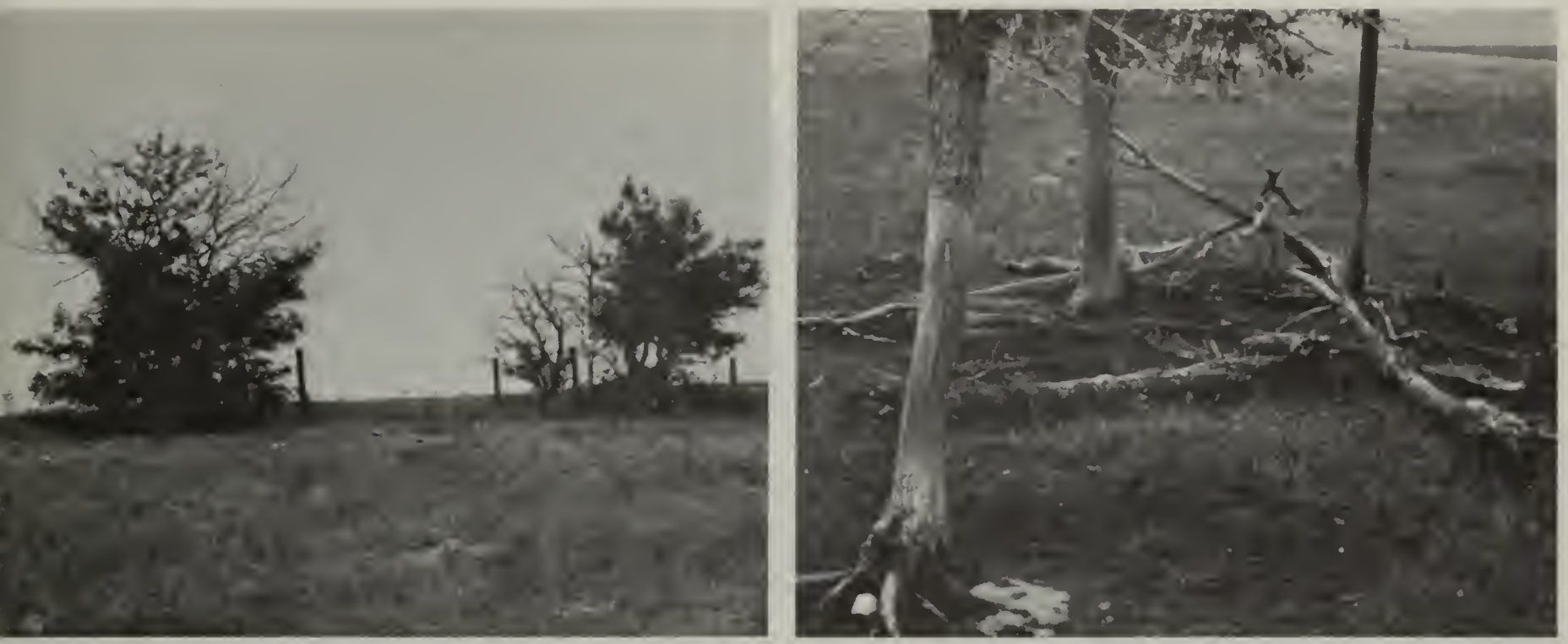

Figure 16. Fenced and unfenced trees containing raptor nests. Unfenced trees are almost dead because of cattle abuse.

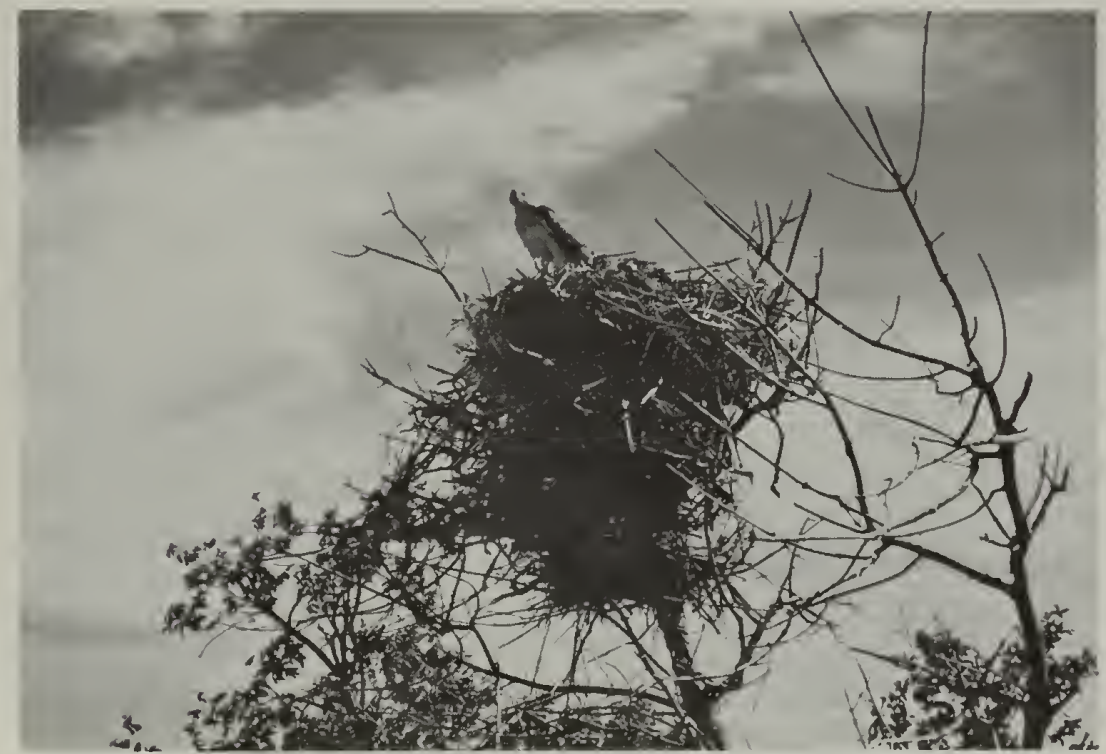

Figure 17. Very large active ferruginous hawk nest in very small tree. Building a support under nest might preserve nest for many years; otherwise it will soon topple. 
Figure 19 shows a great horned ow 1 nest which was a reconstructed ferruginous hawk nest (Anderson, 1979, personal commun.). Bill Anderson reconstructed the nest to make it more permanent for ferruginous hawks, but it was taken over by great horned owls in 1979. The author observed three ferruginous hawk nests that were taken over by great horned owls during the early spring of 1979.

Great horned owls will utilize old stick nests in a wide variety of settings, sometimes even in low, dead trees having no foliage cover. Bohm (1977) had good acceptance of artificial nest structures by great horned owls in central Minnesota. The nests were made of $1 \mathrm{~m} \times 1 \mathrm{~m}$ pieces of $2.5 \mathrm{~cm}$ mesh chicken wire. A $1 \mathrm{~m} \mathrm{x} 1 \mathrm{~m}$ piece was formed into a shallow cone by cutting from its center to one of the corners and then overlapping the edges. The completed cone measured approximately $75 \mathrm{~cm}$ (top diameter) by approximately $45 \mathrm{~cm}$ (depth); its shape was secured by bending the sharp wire ends around the wire that they overlapped. The cone was then lined with tar paper and provided with a drainage hole at the base before nest material was added. Bohm (1977) felt that unlined nests were much more susceptible to weathering. His artificial nests consisted of twigs, leaves, and branches, with the finer material near the top where the eggs would be laid. Larger branches were interwoven with each other and the chicken wire as tightly as possible to provide a solid nest structure. Once the entire nest was complete, it was then tied to a rope, pulled up into a tree, and secured in a suitable crotch with wire and/or large staples. Red-tailed hawks tend to nest near the tops of trees, but great horned owls will nest at practically any elevation above the ground. Nests that are constructed primarily for the larger owls should be in place by early January since most owls will begin establishing their nesting territories very early in the year.

Long-eared owls and great gray owls will also accept artificial nest structures (Nero, 1977). In the bogs of southeastern Manitoba, Nero (1977) had placed more than 60 artificial nest structures in trees, mostly tamaracks, by 1977. Nest heights varied from 15 to 40 feet above the ground and they were widely accepted by great gray owls. He employed a wire-mesh screen for the nest base, placing it in trees having suitable crotch arrangement to support the structure. Ideal trees consisted of deformed tamaracks having crowns of upright limbs that formed cradles in which the nests could be constructed.

Golden eagle nests in trees become bulky and very heavy over a period of years and often break the branches that support them. Some raptor biologists have removed such nests, constructed solid bases of wood or wire mesh, and then placed the nests back on the structures. Where feasible, this kind of work may increase the useful life of eagle nests by many years. Figure 20 illustrates a golden eagle nest in northern Colorado where Gerald Craig and Bill Anderson constructed a 

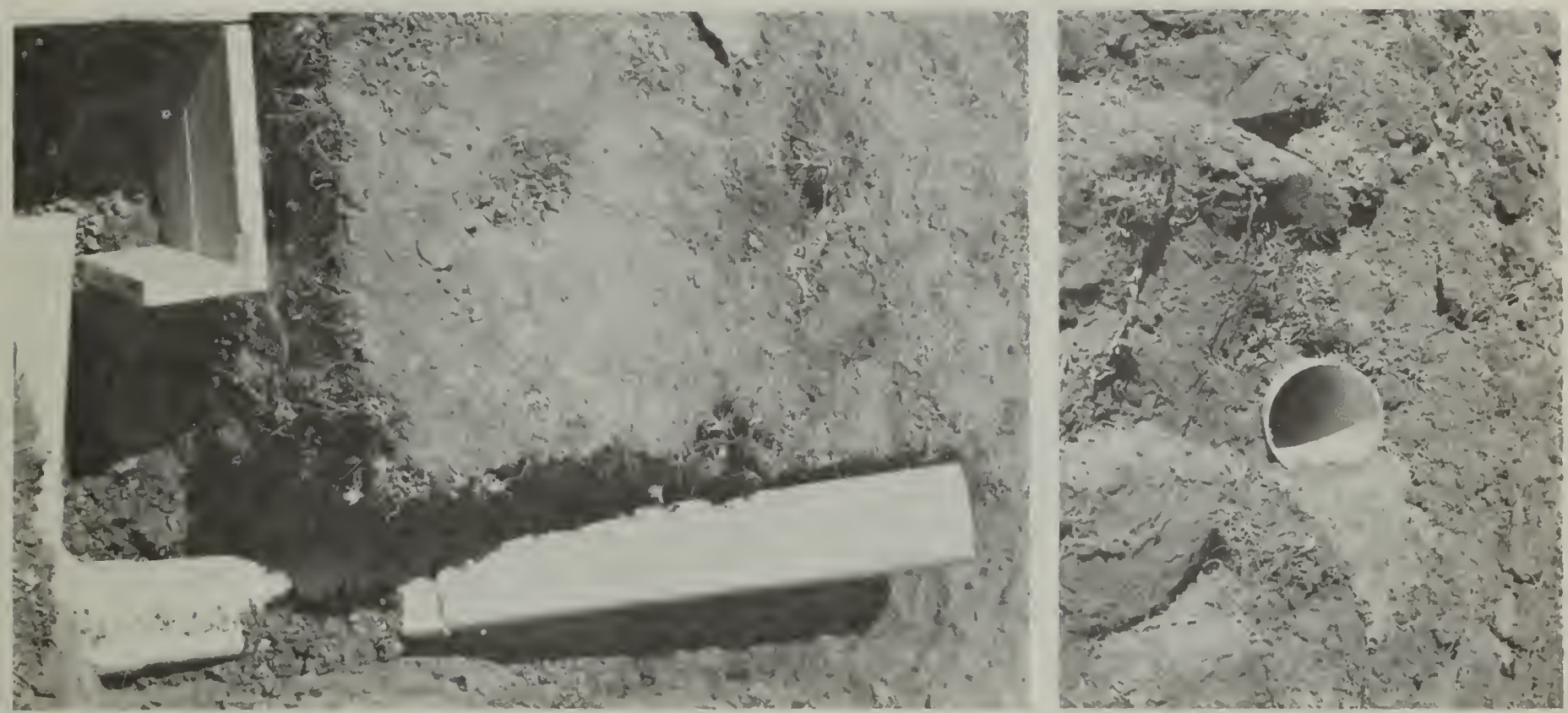

Figure 18. Artificial nesting burrow constructed for burrowing owls by Curtis Orde, Pawnee National Grasslands, Colorado.

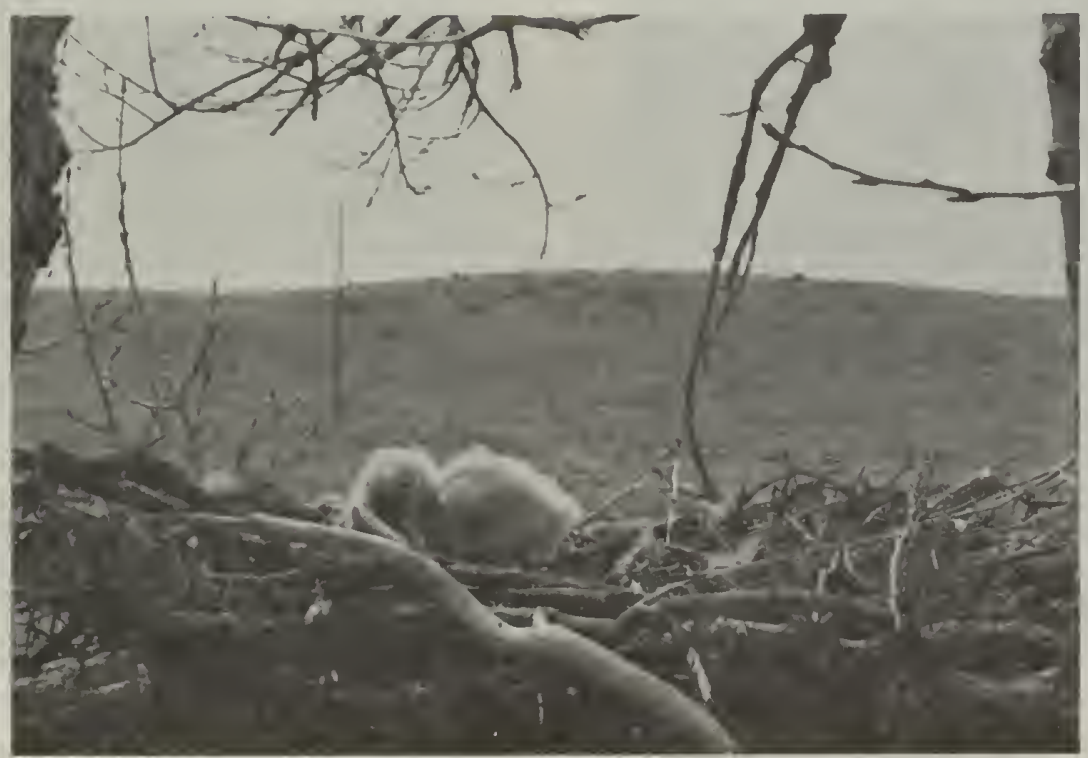

Figure 19. Young great horned owlets on reconstructed ferruginous hawk nest that had been used for several previous seasons by hawks. 


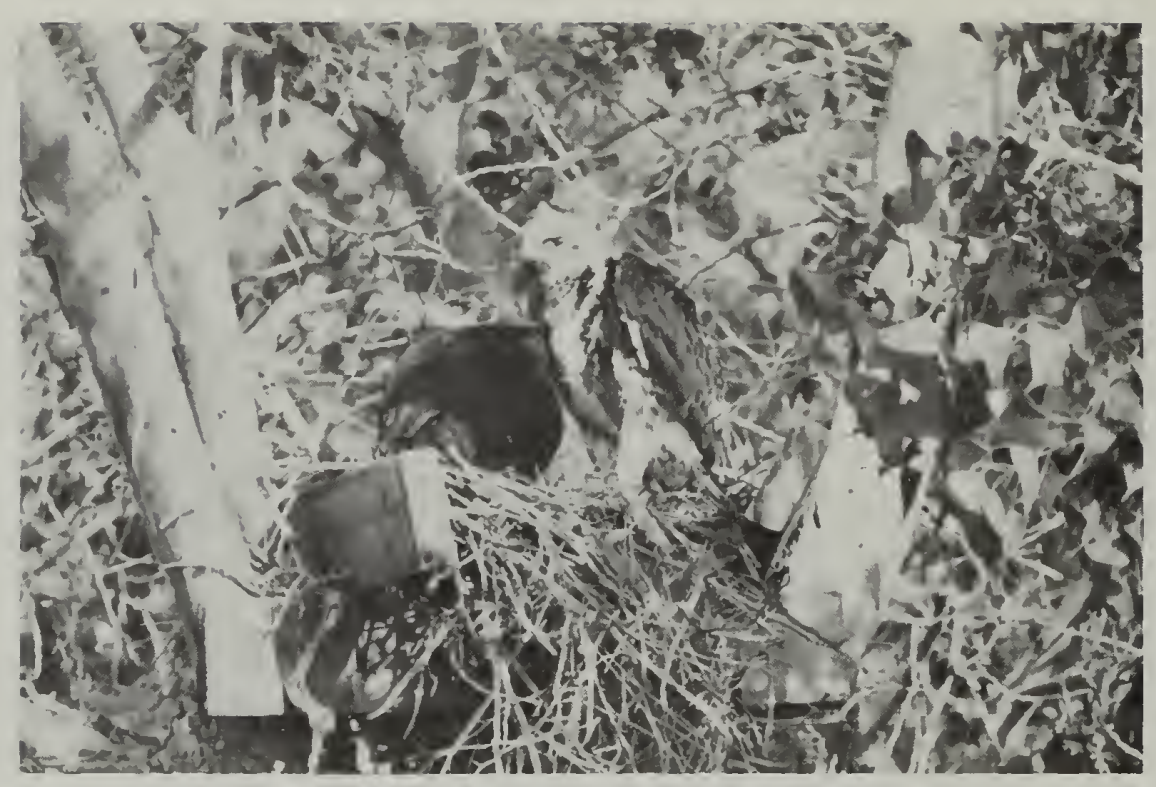

Figure 20. Golden eagle nest in northern Colorado which was reconstructed and provided with stable base to assure more permanent nest.
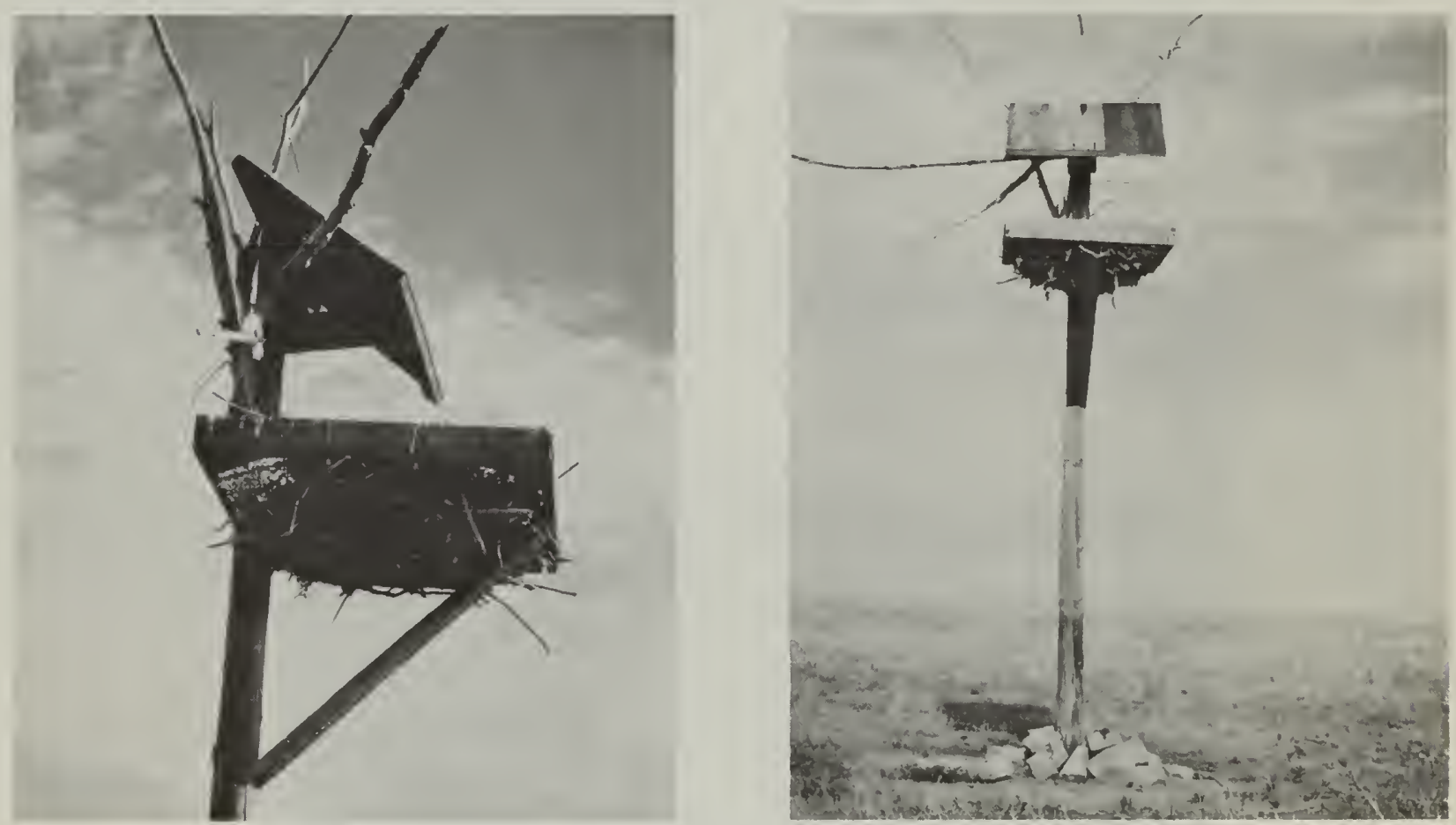

Figure 21. Artificial nesting platform used by golden eagles in northern Colorado, Pawnee National Grasslands. To date, use of such structures by golden eagles has been rare. 
solid base and the eagles continued to use the nest. Figure 21 shows an artificial nesting platform on the Pawnee National Grasslands of northern Colorado that successfully fledged one eaglet in 1979. The eaglet was still on the nest on August 5, which might indicate a re-nesting of this pair. Use by golden eagles of artificial nesting structures such as this one is fairly rare.

Some workers have had success inducing bald eagles to use reconstructed nests or artificial nesting structures (Postupalsky, 1977; Grubb, 1978, personal commun.; Dunstan and Borth, 1970). Figures 22 and 23 show the structures built by Terry Grubb in Arizona, with the adult bald eagle on eggs on one of the artificial nests. It sometimes requires several years for bald eagles to accept and use nest platforms (Postupalsky, 1977), but Grubb (1978, personal commun.), in cooperation with personnel from the U.S. Fish and Wildlife Service, succeeded in attracting bald eagles to nest on a tripod structure the first spring it was in place. In the case of Postupalsky (1977) and Dunstan and Borth (1970), bald eagle nests fell from decadent trees and were reconstructed by these workers in nearby healthy trees. In the case of Grubb (1978, personal commun.), the eagles built a nest in a flimsy snag which blew down. He and his associates then decided to construct a strong tripod-shaped affair which would be permanent. They reconstructed the nest in the top portion of the structure and it was accepted by the eagles the first year thereafter. Two eggs were laid but, unfortunately, no young were successfully fledged.

Artificial nests for bald eagles should be placed in either historical or active nesting territories if one expects to attract nesting eagles to the structures.

Many persons have worked on maintenance or improvement of habitat for ospreys. Lehenbauer (1966) and others recognized that "Two habitat factors are of prime importance: (1) numerous snag nesting sites and (2) an abundant fish food supply. Any wide-scale alteration to either of these factors would significantly affect the welfare of the osprey." Land managers usually recognize that protection of existing nest sites and food supply are essential elements in management programs if ospreys are to be maintained in an area. Obviously, these goals have to be coordinated with other planned uses of the area.

If ospreys have habitually used an area, it probably has an adequate food source. However, fish populations in the area should be checked to determine species, status, and trends. Maintaining adequate fish sources will be essential to maintaining the osprey population and should be coordinated closely with the state wildlife agency. 

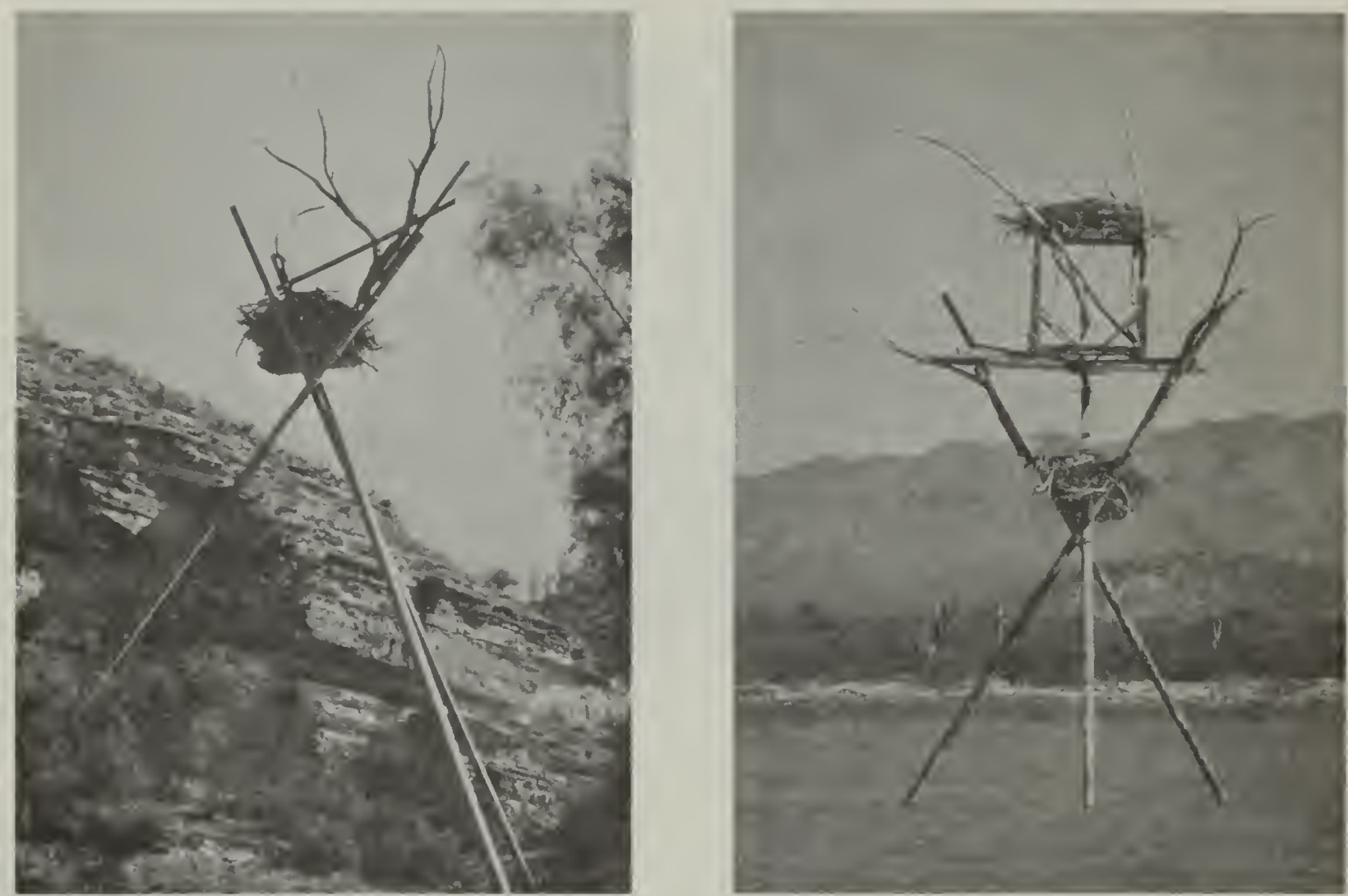

Figure 22. Two tripod-type nest structures built for bald eagles in Arizona.

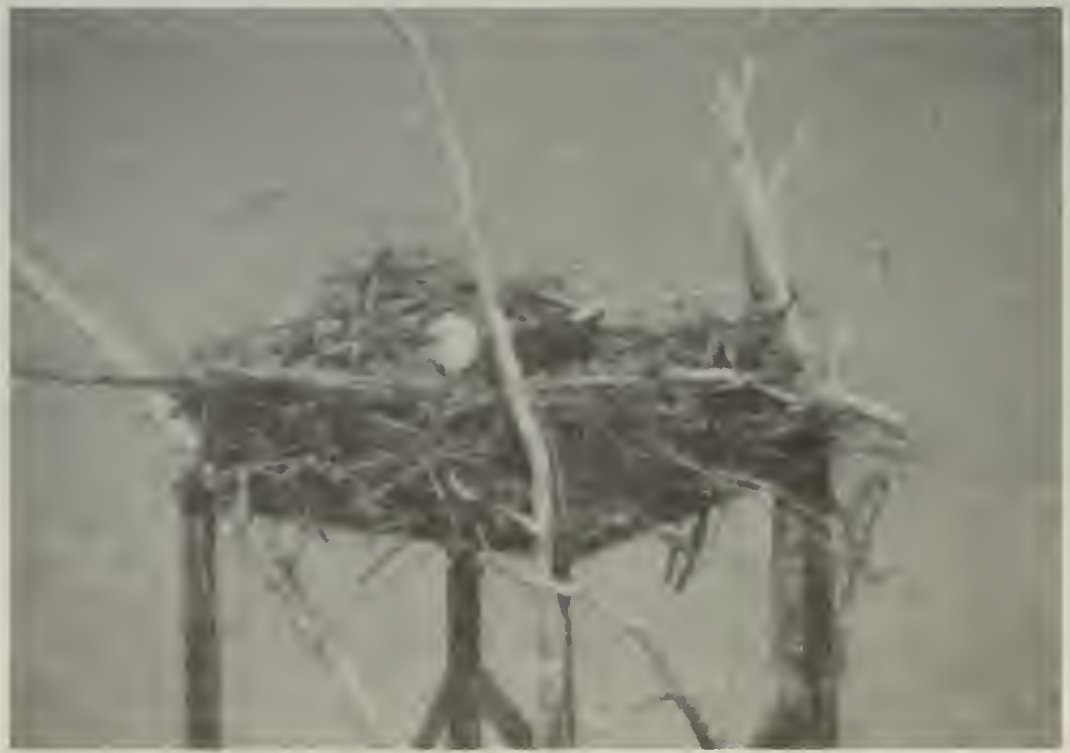

Figure 23. Bald eagle incubating eggs on artificial nest shown in Figure 22, right-hand photo. 
Maintenance of osprey nesting sites is the second most important consideration. Areas having adequate fish supplies but lacking nesting sites or where present nesting snags are falling might benefit through the construction of artificial nesting platforms (Zarn, 1974).

Artificial nesting platforms should offer an elevated, unrestricted view and access to a food supply. Platforms intended to replace a deteriorated nest snag should be placed reasonably close to the snag. Additional nest sites may be developed in suitable areas where none are available.

Several workers have constructed nesting platforms that have been accepted by ospreys (Postupalsky and Stackpole, 1974; Reese, 1970; Bent, 1961; Kah1, 1971, 1972; Johnson and Melquist, 1973; Roberts, $1969,1970)$. Their general recommendation is that the optimum size and location of nesting platforms need to be determined through experimentation and analysis of active nest sites within the area. Means for preserving natural snags may vary between areas because of differences in size of snags, height of trees, proximity to water, degree of decay of the snags, or other factors.

New reservoirs in mountainous or other tree-lined areas often inundate shoreline trees that eventually drown and die. The resultant snags may provide ideal nesting sites for ospreys, but these too begin rotting at the waterline and fall down or blow down over a period of years. In some high-use nesting sites, such as Craine Prairie Reservoir in Oregon, the management plan proposes methods for prolonging the usable life of the snags by installing guy wires, tripod braces, and telephone pole stubs (Roberts, 1969). As substitutes for natural snags, they have suggested the construction of nest platforms atop treated timbers or aluminum poles. The possibility of creating snags by girdling or poisoning dominant trees in adjacent green buffer strips was also considered. Artificial nesting structures would then be constructed in the tops of these snags if necessary for nest support. Removing tops from suitable living or dead trees increases their attractiveness to ospreys (Kah1, 1972). Figure 24 shows how dead trees are "topped" to provide bases for osprey nests, and Figure 25 shows young ospreys on an artificial nesting platform.

Construction of artificial nesting platforms for ospreys (or other raptors) in areas that are not within the known traditional nesting range of the birds has been considered by some biologists. If the structures are placed near the boundaries of known nesting ranges, they may offer the possibility of extending osprey (or other raptor) nesting ranges if food supplies are adequate but natural nesting sites are not available. For example, ospreys nest in Mexico and in various parts of the western United States. Portions of the lower Colorado River, while appearing suitable except for the absence of nesting sites, apparently have not been used in recent times. Construction of nesting platforms in such areas may invite passing ospreys to stop for the nesting season. 


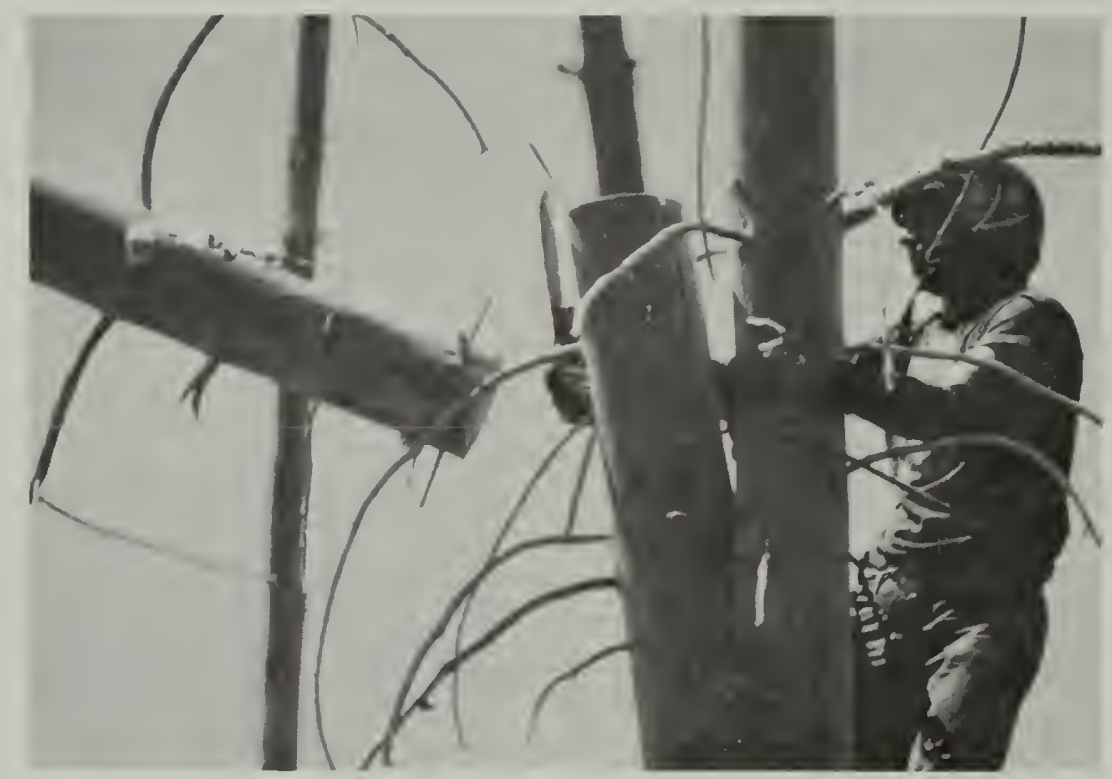

Figure 24. Oregon biologist "topping" a dead snag to provide nest base for ospreys.

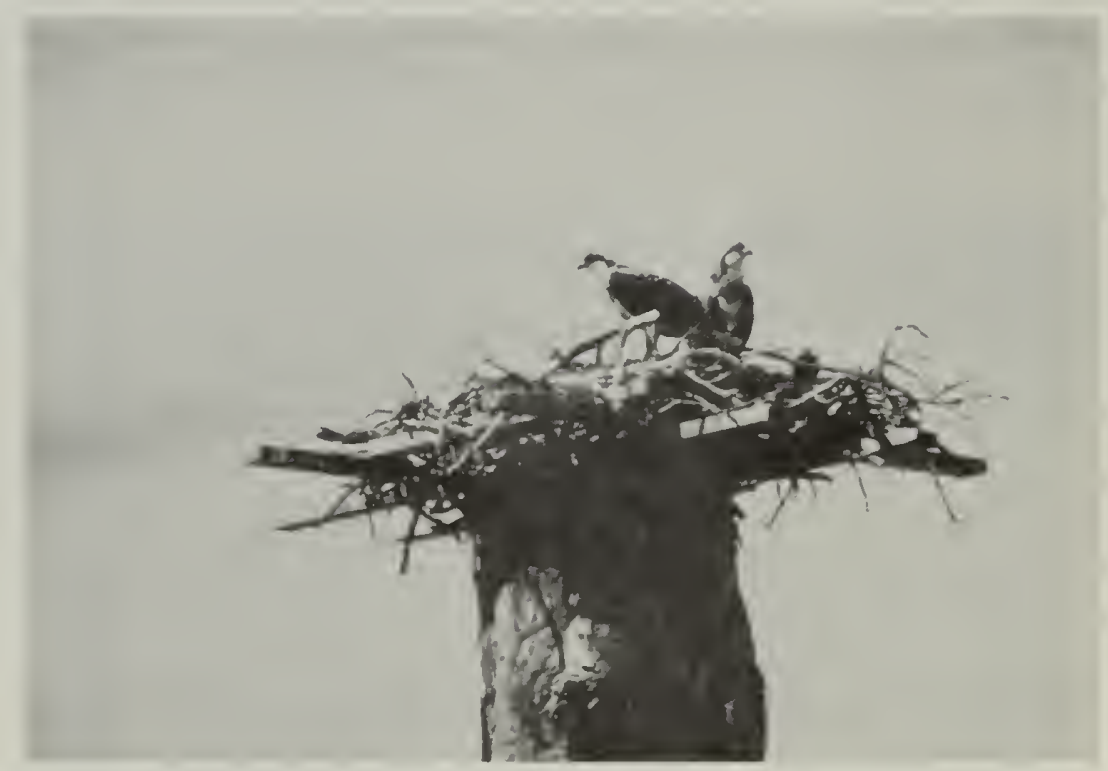

Figure 25. Young ospreys on artificial nest structure in Oregon. 
Cavity-Nesting Species--Several species of raptors utilize cavities for nesting in trees, dirt banks, cliffs, or buildings. Many species that use such sites have already been discussed as cliff-nesting species and will only be discussed here in relationship to their use of artificial nesting boxes. The small owls normally use flicker or woodpecker holes in trees, saguaro cacti, or other treelike vegetation. Included are the screech, saw-whet, elf, pygmy, ferruginous, flammulated, and boreal owls. Larger owls that sometimes use cavities for nesting include the great horned, barred, spotted, hawk, and barn owls (Fig. 3).

All of the falcons could conceivably be attracted to artificial nesting cavities (boxes or barrels of one kind or another). Olendorff and Stoddart (1974) discussed the possibility of using wooden barrels hung over the sides of cliffs, on power poles, or in trees to attract nesting prairie falcons. To my knowledge, no one has successfully accomplished this yet. Fyfe (personal commun.) has tried to attract prairie pigeon hawks to nest boxes in Canada but has had no positive results yet. Because of recent declines in numbers of peregrine falcons, it is unlikely that their populations are limited by nesting sites and it would seem unfeasible to attempt to attract them to nest in boxes on cliffs.

Kestrels are reasonably easy to attract to nest boxes of appropriate size. Numerous workers throughout the United States and Canada have constructed large numbers of kestrel boxes and achieved a high degree of occupancy (Henney, 1979, personal commun.; Hamerstrom, Hamerstrom and Hart, 1973; Woyda, 1977; U.S. Bureau of Land Management, 1978, personal commun.) Nest boxes for kestrels should be placed in reasonably open areas, such as openings in forests, along prairie or desert fences, on the borders of towns and ranches, etc. (Fig. 27). The author was successful in attracting a nesting pair to an aspen birdhouse placed on his home in Littleton, Colorado, where there is an open field on one side of the house (Fig. 26). The section of aspen was an old flicker nest. Such a cavity is the type normally used by kestrels in the wild, and the results were probably typical. Five kestrels hatched and survived for about one week, but only three of the five ultimately fledged. I suspect the other two either suffocated or received too little food to survive. Their remains were not found. As with most other raptor species, the last one or two birds that hatch have a tough time competing.

Most researchers construct kestrel boxes approximately 20 to 24 inches high and about 10 inches square, with a 3-to-4-inch hole about $3 / 4$ of the way up from the floor. This is much larger than a natural flicker cavity and provides additional space for the young. In the wild, many kestrels use natural cavities in trees that provide them with additional room for the young. Lack of suitable nesting cavities seems to be limiting the kestrel population in some areas. In such areas the 


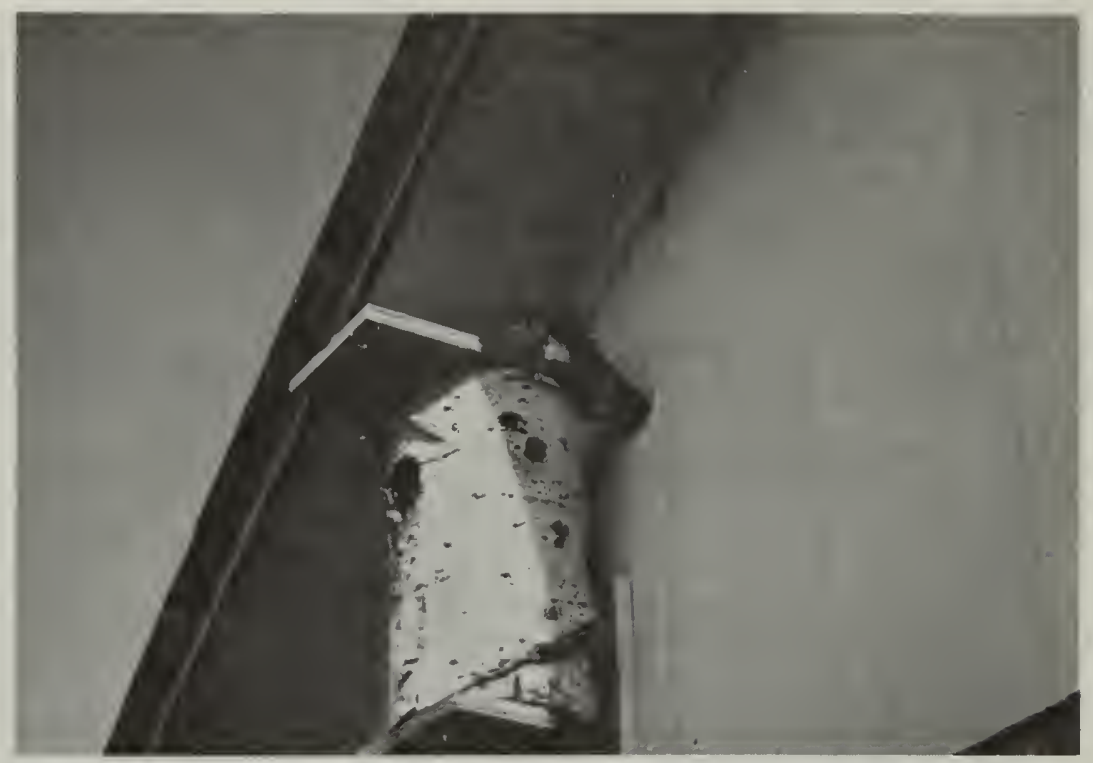

Figure 26. Section of aspen containing flicker nest cavity was placed on author's house in early winter 1979. Pair of kestrels utilized cavity as nesting site and fledged three young in 1979.
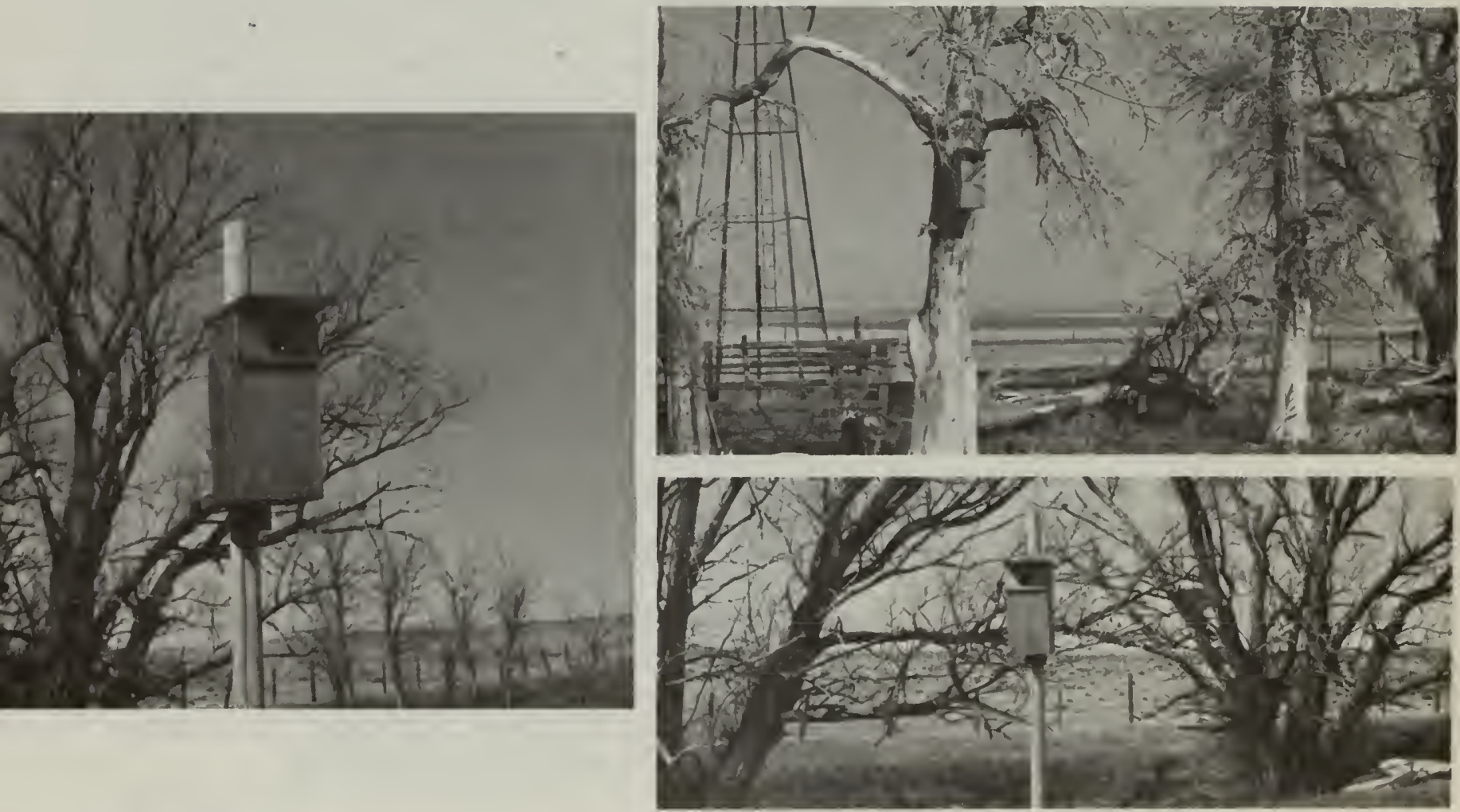

Figure 27. Kestrel boxes placed in good locations to attract nesting birds. 
reason for this should be identified before a lot of work is expended on constructing and placing nest boxes across the countyside. Also, the decline may be caused by something other than lack of nesting cavities.

Screech owls also utilize nest boxes placed in woodlots or clumps of trees. While they do not accept the boxes as readily as kestrels, some workers have had good success in their use (Henney, 1979, personal commun.). Saw-whet owls will also sometimes use them, with pygmy owls apparently less receptive of artificial boxes. More research needs to be conducted on the acceptability of nest boxes by other small owls.

Species Nesting Underground--The only species of raptor that truly nests underground in open prairies or deserts is the burrowing owl. It normally utilizes old prairie dog, rabbit, or other rodent burrows but will accept artificial burrows. Landry (1977) had considerable success in their use at the Seal Beach Naval Weapons Station in Orange County, California. Other workers are presently testing their use (Orde, 1979, personal commun.)(Fig. 18). Several pairs of burrowing owls may live in the same prairie dog colony. Sometimes such colonies are completely destroyed by poisoning, plowing, or building homes on the land where the colony existed.

The status of the burrowing owl throughout much of the West is still uncertain. Therefore, protection of known nesting areas should be provided until trends in their populations are better known. Areas in which artificial nesting structures are placed should be free of any high vegetation, either grass or shrubs, so they can be found by the owls. Prairie dogs will sometimes fill up the openings with dirt, so they should be checked frequently during the spring to be sure they are serviceable.

Use of Man-Made Objects for Nesting Sites

A wide variety of raptors are sufficiently adaptable to be able to use various man-made structures as nesting sites. Some of them are as follows:

Golden eagle -- observation platforms, railroad abutments, steel and wooden power poles, and abandoned quarries.

Osprey -- steel and wooden power poles, offshore duck blinds, channel markers, and pilings.

Peregrine falcon -- abandoned shooting platforms and shallow willow baskets placed in trees in Germany, stone ledges, and concrete buildings.

Prairie falcon -- stone sheepherder monuments. 
Gyrfalcon -- gold dredges and other mining structures.

Kestrel -- building eaves, flicker holes in walls, and nesting boxes.

Ferruginous hawk -- metal-roofed building in deserts, top of stone chimneys, steel and wooden power poles, windmills, water control structures at reservoirs, upper platforms of pumping stations, haystacks, sheepherder monuments, and uranium spoil piles.

Red-tailed hawk -- steel and wooden power poles.

Swainson's hawk -- steel and wooden power pole structures and windmills.

Turkey and black vultures -- inside abandoned buildings.

Common raven -- in bridge structures, windmills, pumping stations, steel and wooden power poles.

Great horned owl -- in abandoned buildings (attics), silos, in old nests on steel and wooden power poles, abandoned quarries, and abandoned mine buildings.

Screech, saw-whet, and pygmy owls -- bird boxes.

Barn owl -- silos, barns, abandoned buildings, water towers, abandoned mining shafts, church steeples, old wells, and concrete plants.

The use of such man-made structures, not intended as bird nesting sites, is generally widespread with regard to species and geography (Fig. 28). A high percentage of ferruginous hawks reported by Gilmer and Wiehe (1977) were nesting either on steel transmission line towers or on haystacks in North Dakota, but these are relatively uncommon nesting sites for the West as a whole. While more that $90 \%$ of the ferruginous hawks in southern Wyoming probably nest on the ground or on rocky outcroppings, pinnacles, or boulders, from two to three nests each year are located on wooden power poles.

Nelson (1978) began testing the use of artificial nesting platforms for golden eagles in 1975. Noting that several species of birds, including golden eagles, ospreys, red-tailed hawks, ferruginous hawks, and ravens, were using steel and wooden transmission line towers for nesting, he reasoned that well-constructed nesting platforms on the towers would provide the needed nesting sites and also create less chance for power outages that could occur from nesting materials. His 

preferred design is as shown in Figure 29 and is shown in place in Figures 30 and 31. Working with the Bonneville Power Administration and the Idaho Power Company, he erected six platforms prior to the 1977 nesting season on lines with voltages up to 720,000. All platforms were between 75 feet and 175 feet above the ground. Of the six installed nesting platforms, five nesting attempts were made. Three were successful (for a red-tailed hawk, golden eagle, and osprey), while two were unsuccessful (for an osprey and a bald eagle). The platforms were placed on power poles in habitat types that would be acceptable to the species involved.

Nelson (1978) emphasized the importance of shade and protection from the wind in exposed sites. In hot desert areas, young golden eagles, red-tailed hawks, and prairie falcons may die from overheating if shade is not available for at least the head and shoulders. Shelter from the wind also appears to be beneficial to eagles and red-tailed hawks, but ferruginous hawks and ospreys seem to have no requirement for protection from either the sun or the wind.

Use of man-made structures for nesting seems to occur most where natural nesting sites are scarce. The use of these kinds of structures implies that artificial nesting structures will be most acceptable where normal nesting substrates are scarce or unavailable, such as in deserts, grasslands, tundra, or low shrub areas. There is little reason for erecting artificial nesting stmctures where normal nesting sites are plentiful. 


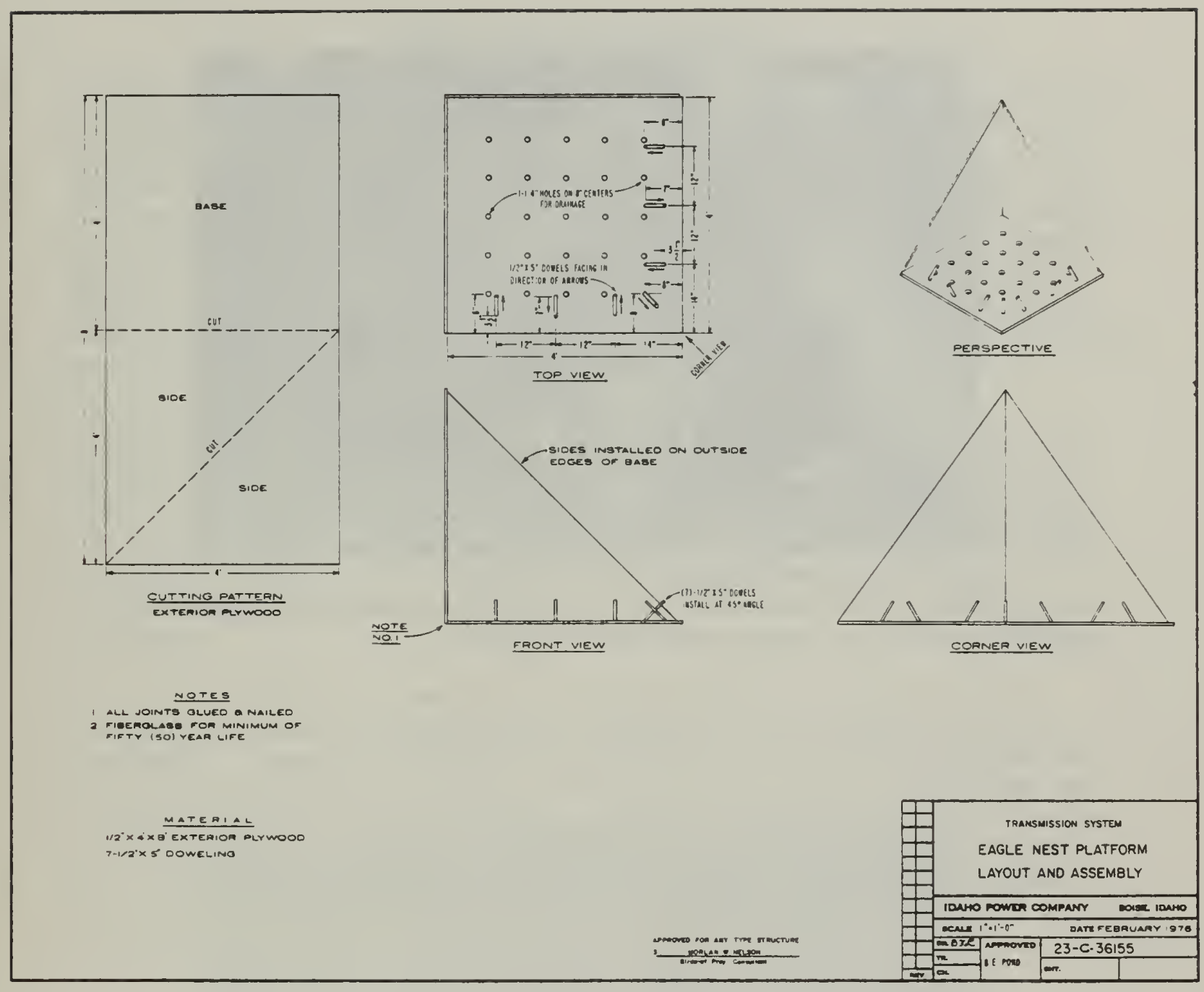

Figure 29. Eagle nest platform layout and assembly (from Nelson, 1978). 


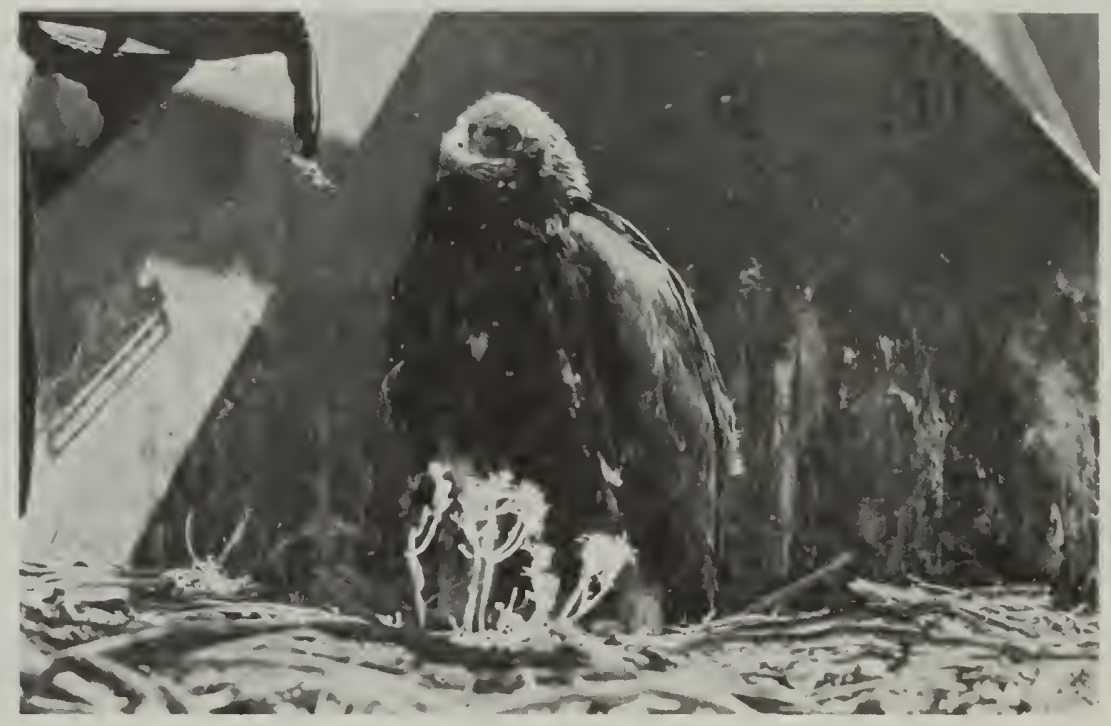

Figure 30. Close-up view of nesting structure designed by Nelson (1978) for eagles and other raptors.

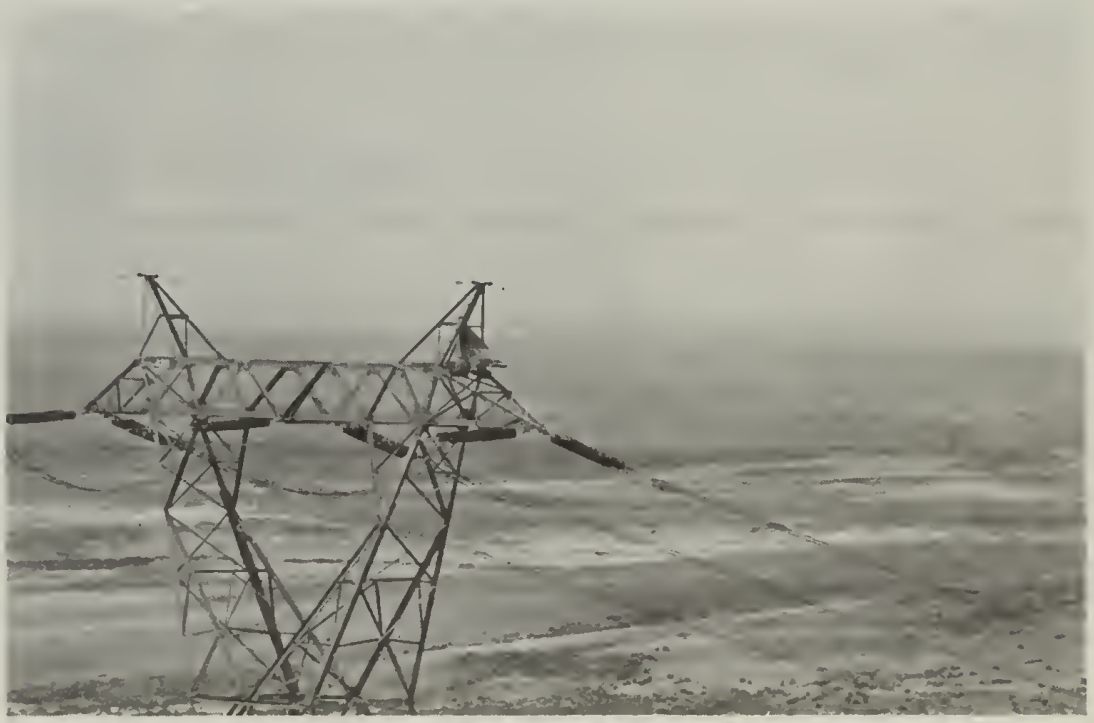

Figure 31. Nesting structure for eagles and other raptors in place on steel transmission tower in Idaho. 


\section{PUBLIC AND I \& E PROGRAMS}

Until recent years, man has tended to view raptors mainly as predators of game and livestock. Even game law enforcement agents tended to consider birds of prey more as enemies of game species, such as ducks, grouse, doves, etc., than as favored species in their own right. One law enforcement official for the Wyoming Game and Fish Commission that the author talked to 20 years ago had "personally killed more than 40 golden eagles" in that single year. His reasoning was that eagles "kill ducks, grouse, and other game birds." The slaughter of golden eagles in the early 1970 s by livestockmen in Wyoming, Texas, and other states is well known.

During the last decade or two there has been a growing interest in raptors by Nature enthusiasts, biologists, enforcement agents, and conservationists. Those wishing to use birds of prey for falconry have also grown in numbers. Persons interested in raptors recognize a multitude of values of these birds, including scientific, ecologic, economic, and esthetic. Several TV programs have beautifully illustrated different species and helped to create additional public interest.

Efforts to inform the public of the many values of raptors must continue if general preservation goals for these species are to be realized. There will always be unthinking, uncaring individuals in our society who will continue to destroy that which is beautiful to others. But there are many other thousands whose hearts are waiting to be tuned in to conservation philosophies and whose inner beings will ultimately thrill to the sights and sounds of Nature. These are the ones that may be reached by continuing public education programs. 


\section{LAW ENFORCEMENT}

The new migratory bird treaty between the United States and Mexico, signed in 1972, placed all birds of prey under Federal jurisdiction and protection. In addition, most states have specific laws protecting all or most birds of prey. Laws, however, are only as good as enforcement capability of those laws which can never be total or complete. Irresponsible trappers and hunters will continue to rise from upcoming generations; activities will take them into isolated areas that may be separated greatly both in time and distance from the nearest wildlife enforcement agents. While law enforcement and violators' apprehension play a vital role in preventing more widespread shooting and general irresponsibility towards wildlife, the greatest rewards will come from increasing emphasis on public education. Conservationists across the country have been assisting in providing lectures and training to children in public schools, both thru good visual programs and by bringing live raptors into the classroom. Building empathy in our youth now will hopefully create less need for enforcement in the future. 


\section{LITERATURE CITED}

Anderson, R.D. 1972. Curlew Valley Validation Site Report, 1972

Progress Report: Research Memorandum, Desert Biome, USIBP:

Utah State University, pp. 144-168.

Bent, A.C. 1937. Life histories of North American birds of prey, Part I: Smithsonian Institution USNM Bull. 167, 409 p.

1961. Life histories of North American birds of prey, Part I (revised 1937 ed.): Dover Publ., Inc., New York. 409 p.

Bohm, R.T. 1977. Artificial nest platforms for raptors. Raptor Research: V. 11, no. 4, pp. 97-99.

Brown, L. 1974. Data required for effective study of raptor populations in Management of raptors; Hamerstrom, F.N., Jr., and others, eds., Raptor Research Report No. 2: Raptor Research Foundation, Inc., Vermillion, South Dakota, pp. 9-20.

Busch, D.E., W.A. deGraw, and N.C. Clampitt. 1978. Raptor Research: V. 12, pp. 122-125.

Cal1, M.W. 1978. Nesting habitats and surveying techniques for common Western raptors: BLM Technical Note No. 316, Bureau of Land Management, Denver Service Center, Denver, Colorado.

Christensen, R.C. 1972. Raptor predation on pocket gopher populations by the use of hunting perches (Unpub. M.S. thesis): Brigham Young University, Dept. of Zoology, Provo, Utah, 87 p.

Craighead, J.J., and F.C. Craighead. 1956. Hawks, owls and wildlife: Stackpole Co., Harrisburg, Pa., 443 p.

Dunstan, T.C., and M. Borth. 1970. Successful reconstruction of active bald eagle nest: Wilson Bull. V. 82, no. 3, pp. 326-327.

Ellis, D.H., D.G. Smith, and J.R. Murphy. 1969. Studies on raptor mortality in western Utah: Great Basin Nat., V. 29, pp. 165-167.

Eng, R.L., and G.W. Gullion, 1962. The predation of goshawks upon ruffed grouse on the Cloquet Forest Research Center, Minnesota: Wilson Bull., V. 74, pp. 227-242. 
Fyfe, R.W., and H.I. Armbruster. 1977. Raptor research and management in Canada, in Proceedings, World Conference on Birds of Prey: Vienna, pp. 282-293.

Fyfe, R.W., and R.R. Olendorff. 1976. Minimizing the dangers of studies to raptors and other sensitive species: Occasional Paper No. 23, Canadian Wildlife Services, Ottawa.

Garber, D.P., J.R. Koplin, and J.R. Kahl. 1974. Osprey management on the Lassen National Forest, California, in Management of Raptors; Hamerstrom, F.N., Jr., and others, eds. Raptor Research Report No. 2: Raptor Research Foundation Inc., Vermillion, South Dakota, pp. 119-122.

Gilmer, D.S., and J.M. Wiehe. 1977. Nesting by ferruginous hawks and other raptors on high voltage powerline towers: The Prairie Naturalist, V. 9, no. 1, March 1977, pp. 1-10.

Glue, D.E. 1971. Ringing recovery circumstances of small birds of prey: Bird Study, V. 18, pp. 137-146.

Hamerstrom, F., F.N. Hamerstrom, and J. Hart. 1973. Nest boxes: an effective management tool for kestrels. J. Wildl. Manage., V. 37, pp. 400-403.

Henny, C.J., and H.M. Wight. 1970. Red-tailed and Cooper's hawks: Their population ecology and environmental pollution. Symposium: Population Ecology of Migratory Birds: Patuxent Wild. Res. Cent.

Hodson, K. 1975. Some aspects of the nesting ecology of Richardson's merlin on the Canadian prairie (M.A. thesis): University of British Columbia, Canada.

Howard, R.P. 1975. Breeding ecology of the ferruginous hawk in northern Utah and southern Idaho (M.S. thesis): Utah State University, Logan, Utah, $70 \mathrm{pp}$.

Johnson, D.R., and W.E. Melquist. 1973. Unique, rare and endangered raptorial birds of northern Idaho: Nesting success and management recommendations: University of Idaho and USDA Forest Service, Publ. No. Rl-73-021, $42 \mathrm{pp}$.

Jones, S. 1979. The accipiters. Habitat Management Series for Unique or Endangered Species, Report No. 17: U.S. Bureau of Land Management, Denver Service Center, Denver, Colorado.

Kahl, J.R. 1971. Osprey habitat management plan, Lassen National Forest, 1971: Lassen National Forest, Susanville, California. 
1972. Osprey management on the Lassen National Forest. California-Nevada Section: The Wildlife Society. 1972 Trans., pp. 7-13.

Lack, D. 1966. Population studies of birds: Clarendon Press, London. $341 \mathrm{p}$.

Landry, R.E. 1977. Growth and development of the burrowing owl, Athene cunicularia: Presented at the Raptor Research Foundation Annual Meeting, Nov. 11-14, 1977, Tempe, Arizona.

Lehenbauer, P.A. 1966. Reconnaissance report, wildlife enhancement program, proposed snag removal project, Crane Prairie Reservoir: Division of Wildlife Series, Bureau of Sport Fisheries and Wildlife, Portland, Oregon. Typewritten, 6 p.

Murphy, J.R. 1978. Management considerations for some western hawks: Trans. 43rd North American Wildlife and Natural Resources Conference, Wildlife Management Institute, Washington, D.C.

Nelson, M.W. 1978. Bird of prey management techniques, T.G. Geer, ed.: British Falconers' Club, London. pp. 42-46.

Nero, R.W. 1977. Great gray owl nests: Manitoba Nature, Winter 1977, pp. 4-11.

Olendorff, R.R., and J.W. Stoddart, Jr. 1974. The potential for management of raptor populations in western grasslands, in Management of raptors; Hamerstrom, F.N., Jr., and others, eds.: Raptor Research Report No. 2, pp. 44-88.

Owens, R.A., and M.T. Myers. 1973. Effects of agriculture upon populations of native passerine birds of an Alberta fescue grassland: Canadian Journal of Zoology, V. 51, pp. 697-713.

Patterson, R.L. 1952. The sage grouse in Wyoming: Sage Books, Inc., Denver, Colorado, $341 \mathrm{p}$.

Platt, J.B. 1971. A survey of nesting hawks, eagles, falcons, and owls in Curlew Valley, Utah: Great Basin Nat. V. 31, p. 5165.

Postupalsky, S., and S.M. Stackpole. 1974. Artificial nesting platforms for ospreys in Michigan, in Management of raptors; Hamerstrom, F.N., Jr., and others, eds.: Raptor Research Report No. 2, Raptor Research Foundation, Inc., Vermillion, South Dakota, pp. 119-122.

1977. Successful breeding by bald eagles on manmade nests (abs.): Raptor Research Foundation Meeting, 1977, Tempe, Arizona. 
Reese, J.G. 1970. Reproduction in a Chesapeake Bay osprey population: Auk, V. 87, pp. 747-759.

Reynolds, R.T., and H.M. Wight. 1978. Distribution, density, and productivity of accipiter hawks breeding in Oregon: Wilson Bulletin, V. 90, no. 2, pp. 182-196.

Roberts, H.B. 1969. Management plan for the Crane Prairie Reservoir Osprey Management Area: USDA/Forest Service and Oregon State Game Commission, 20 p.

1970. Management of the American osprey on the Deschutes National Forest, Oregon: Raptor Research, V. 4, pp. 168-177.

Shor, W. 1970. Peregrine falcon population dynamics deduced from band recovery data: Raptor Research News, V. 4, pp. 49-59.

Shuster, W. 1979. Northern goshawk nest site requirements in Montane, Colorado: Western Birds (in press).

Smith, D.G., and J.R. Murphy. 1973. Breeding ecology of raptors in the Eastern Great Basin of Utah: Brigham Young University Science Bull., Biol. Ser. V. 18, no. 3, pp. 1-76.

Snyder, N.F.R., and H.A. Snyder. 1975. Raptors in range habitat: Symposium on Management of Forest and Range Habitats for Nongame Birds, Tucson, Arizona, May 6-9, 1975.

Sykes, P.W., Jr., and R. Chandler. 1974. Use of artificial nest structures by everglade kites: Wilson Bull. V. 86, pp. 282-284.

Thomas, J.W., C. Maser, R. Anderson, and others. 1979. Wildlife habitats in managed forests--the Blue Mountains of Oregon \& Washington, Pacific Northwest Forest and Range Experiment Station, USFS, Portland, Oregon.

U.S. Fish and Wildlife Service. 1977. Bald eagle management guidelines, Oregon-Washington: Portland, Oregon.

U.S. Forest Service. 1977. Bald eagle habitat management guidelines: Region 5, San Francisco, California.

White, C.M., and S.K. Sherrod. 1973. Advantages and disadvantages of the use of rotor-winged aircraft in raptor surveys: Raptor Research V. 7, no. 3/4, pp. 97-104.

Woffinden, N.D. 1975. Ecology of the ferruginous hawk (Buteo regalis) in Central Utah: Population dynamics and nest site selection (Ph.D. thesis): Brigham Young University, Provo, Utah, 102 p. 
Woyda, A.L., and J.A. Martin. 1977. The nesting biology of the American kestrel in Cache Valley, Utah (Abs.): Raptor Research Foundation Annual Meeting, 1977, Tempe, Arizona.

Zarn, M. 1974. Osprey. Habitat management series for unique or endangered species: Technical Note No. 254, U.S. Bureau of Land Management, Denver Service Center, Denver, Colorado. 
ADDITIONAL REFERENCES

(Personal Communications)

Anderson, William. 1979. La Junta Junior College, La Junta, Colorado.

Fyfe, Richard, 1979. Western and Northern Region, Canadian Wildlife Service, 10025 Jasper Ave., Edmonton, Alberta, Canada.

Glinski, Richard. 1978. Arizona State University, Biology Dept., Tempe, Arizona.

Grubb, Tery1. 1979. Rocky Mountain Forest and Range Experiment Station, U.S. Forest Service, Tempe, Arizona.

Henney, Charles J. 1979. Pacific Northwest Field Station, U.S. Fish and Wildlife Service, 480 SW Airport Road, Corvallis, Oregon 97330 .

Howard, Richard. 1979. U.S. Fish and Wildlife Service, Boise, Idaho.

Hubbard, John. 1979. New Mexico Dept. of Fish and Game, Sante Fe, New Mexico.

Millsap, Brian. 1978. Phoenix District Office, U.S. Bureau of Land Management, Phoenix, Arizona.

Neitro, William. 1978. Oregon State Office, U.S. Bureau of Land Management, Portland, Oregon.

Orde, Curtis. 1979. District Biologist, U.S. Forest Service, Greeley, Colorado.

Schne11, Jay. 1978. Klondyke, Arizona. Works in Aravaipa Canyon.

U.S. Bureau of Land Management. 1978. Susanville District, California.

Wagner, Phil. 1978. Utah Division of Wildlife Resources, Salt Lake City, Utah.

Bureau of Land Management

library

Elig. 50, Denier Federal Center

Denver, CO 80225 
BIN Iiverisy

D-553A, 8uizane 50

Danve: Feder al Cenier

P. 0. BOx 25047

Denver, CO 80225-0047

110 a

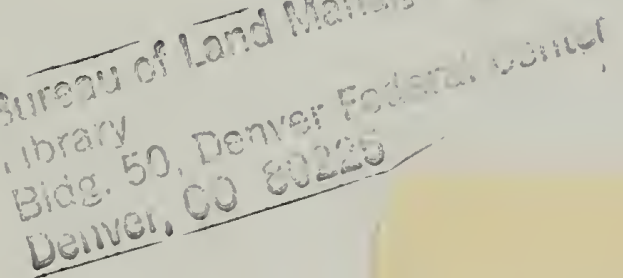

BLW Library

D-853A, Building 50

Denver Federal Center

P. O. Box 25047

Denver, CO 80225-0047 
